\title{
Quinoxaline 1,4-di-N-Oxides: Biological Activities and Mechanisms of Actions
}

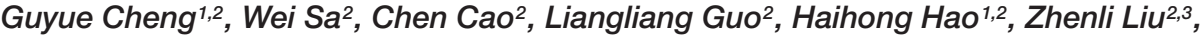 \\ Xu Wang ${ }^{1,2 *}$ and Zonghui Yuan ${ }^{1,2,3 *}$ \\ ${ }^{1}$ MOA Laboratory for Risk Assessment of Quality and Safety of Livestock and Poultry Products, Huazhong Agricultural \\ University, Wuhan, China, ${ }^{2}$ College of Veterinary Medicine, Huazhong Agricultural University, Wuhan, China, ${ }^{3}$ National \\ Reference Laboratory of Veterinary Drug Residues and MOA Key Laboratory for the Detection of Veterinary Drug Residues in \\ Foods, Huazhong Agricultural University, Wuhan, China
}

Quinoxaline 1,4-di-N-oxides (QdNOs) have manifold biological properties, including antimicrobial, antitumoral, antitrypanosomal and antiinflammatory/antioxidant activities. These diverse activities endow them broad applications and prospects in human and veterinary medicines. As QdNOs arouse widespread interest, the evaluation of their medicinal chemistry is still in progress. In the meantime, adverse effects have been reported in some of the QdNO derivatives. For example, genotoxicity and bacterial resistance have been found in QdNO antibacterial growth promoters, conferring urgent need for discovery of new QdNO drugs. However, the modes of actions of QdNOs are not fully understood, hindering the development and innovation of these promising compounds. Here, QdNOs are categorized based on the activities and usages, among which the antimicrobial activities are consist of antibacterial, antimycobacterial and anticandida activities, and the antiprotozoal activities include antitrypanosomal, antimalarial, antitrichomonas, and antiamoebic activities. The structure-activity relationship and the mode of actions of each type of activity of QdNOs are summarized, and the toxicity and the underlying mechanisms are also discussed, providing insight for the future research and development of these fascinating compounds.

Keywords: quinoxaline 1,4-di- $\mathrm{N}$-oxides, antimicrobial, antitumoral, antiprotozoal, antiinflammatory, antioxidant, structure-activity relationship, mode of action

\section{INTRODUCTION}

Quinoxaline is a heterocyclic compound containing a benzene ring and a pyrazine ring. Oxidation of both nitrogens of the pyrazine ring to obtain QdNO offers it variety of biological properties, including antitumoral, antibacterial, anticandida, antitrypanosomal, antiinflammatory/ antioxidant, and mutagenic properties. The versatile activities of QdNOs have aroused

Abbreviations: ADG, average daily gain; BTO, 1,2,4-benzotriazine 1,4-dioxide; BTZ, benzotriazinyl radical; CBX, carbadox; CYA, cyadox; DMPO, 5,5'-dimethylpyrroline 1-N-oxide; DSBs, double-strand breaks; $E(1) \mathrm{R}$, one electron reduction potential; EPR, electron paramagnetic resonance; HIF, hypoxia-inducible factor; HR, homologous recombination; LOX, lipoxygenase; MDR, multidrug resistant; MEQ, mequindox; MIC, minimum inhibitory concentration; NOAEL, no observed adverse effect level; NOS, nitric oxide synthase; ${ }^{\bullet} \mathrm{OH}$, hydroxyl radical; OLA, olaquindox; $\mathrm{O}_{2}^{\bullet-}$, superoxide radical; $\mathrm{QCT}$, quinocetone; QdNOs, quinoxaline 1,4-di-N-oxides; QDX, quindoxin; ROS, reactive oxygen species; SAR, structure-activity relationship; SSBs, single-strand breaks; TB, Tuberculosis; Topo II, topoisomerase II; TPZ, tirapazamine; VEGF, vascular endothelial growth factor; 2DE-MS, two-dimensional polyacrylamide gel electrophoresis combined with mass spectrometry. 
worldwide interests and endowed them potential application in human and veterinary medicines. For example, the QdNO antibacterial growth promoters have been widely used as feed additives to prevent infectious disease and improve animal growth since 1970s (Carta et al., 2005), and the antitumoral drug, TPZ (3-amino-BTO 1,4 dioxide, SR4233), has been subjected to phase II clinical trial (Covens et al., 2006; Maluf et al., 2006; Cohen et al., 2007). Although QdNOs with other activities are still in the research stage, they have exhibited great application prospects.

With the wide use of QdNOs, the toxicity and drug resistance gradually have become the disadvantages for further application of these promising compounds. The molecular targets of quinoxaline derivatives, which is a step beyond simply looking at their activities, should be analyzed. Nevertheless, knowledge about the mode of actions of QdNOs is far from clear, hindering the development of this kind of drugs. Therefore, a detail study on the mode of actions of QdNOs will provide information about the drug targets and the drug action pathway(s) and be helpful to construct models to screen new drugs. Meanwhile, the study of SAR combined with the study of drug action will explain the reason for that different structures of QdNOs exhibit different activities. Furthermore, since most of the drugs have more than one mechanism of action, the deeper study of the drug actions may discover new drug target(s) and provide potential approaches to conquer the problem of drug resistance and to mitigate or avoid toxicity. In this review, the mode of actions of QdNOs and the SAR analysis are elucidated and updated in sort of the different biological properties, giving insight to the future development of these fascinating compounds.

\section{ANTIMICROBIAL ACTIVITIES OF QdNOs}

\section{Antibacterial Activity and Bacterial Resistance}

The antibacterial activity of QdNOs was first reported in McIlwain (1943), and subtherapeutic levels of antibacterial QdNOs have been used for nearly 50 years to promote the growth of animals and improve efficiency of feed conversion in animal husbandry (Carta et al., 2005). As shown in Figure 1, veterinary-used QdNO derivatives include (QdNOs), OLA [2-(N-2'-hydroxyethyl-carbamoyl)-3-methyl quinoxaline 1,4-di- $N$-oxide firstly synthesized by Bayer in 1967], CBX [hydrazine carboxylic acid (2-quinoxalinyl-methylene) methyl ester 1,4-di- $N$-oxide firstly synthesized by Pfizer in 1968]. MEQ (3-methyl-2- quinoxalinacetyl-1,4-di-N-oxide) and QCT (3methyl-2-quinoxalinbenzenevinylketo-1,4-di- $N$-oxide) are novel synthetic QdNO derivatives developed by Lanzhou Institute of Animal Husbandry and Veterinary Drugs, Chinese Academy of Agricultural Sciences (Lanzhou, China). CYA [cyan acetic acid (1,4-di-N-oxy-quinoxalin-2-ylmethylene] hydrazide firstly designed by Chemapol Benelux) is a new QdNO member which is being evaluated in clinical trials for animals in China.

Olaquindox exhibits wide spectrum of antibacterial effect, strongly inhibiting the growth of Escherichia coli, Proteus,
Pasteurella, and dysentery spirochete (Drumev, 1981). Because of its genotoxic potential, OLA is not permitted to use in foodproducing animals in the European Union and Canada (WHO, 1994; European Union [EU], 1998; Standing Committee for Animal Nutrition [SCAN], 1998). CBX shows good therapeutic effect on swine dysentery caused by Brachyspira hyodysenteriae (Rainier et al., 1973a,b; Downing, 1974) and also has good antibacterial effects against Salmonella, E. coli, and other Gramnegative bacteria (Troutt et al., 1974; Das, 1984). CBX was once used as growth-promoting feed additives for piglets or pigs at growing phase (Yen and Pond, 1993) before it was prohibited by the European Union [EU] (1998) because of its mutagenic effects, developmental and reproductive toxicity and carcinogenicity (WHO, 1991; European Union [EU], 1998). In view of the significant effect of CBX on swine dysentery and bacterial enteritis, the United States, Canada, and other countries still allow it used as therapeutic agents. MEQ, which shows good antibacterial activity against Gram-negative bacteria, especially Salmonella, has been widely used in China as an animal feed additive and veterinary medication for diseases, such as swine dysentery and piglet white diarrhea (Liu et al., 2012). QCT is active against $B$. hyodysenteriae, and is also effective against Salmonella, E. coli, and other Gram-negative bacilli. In China, QCT is used as a growth promoting agent for pigs, poultry, and aquatic and has been approved as an animal growth promoter in China since 2003 (Ministry of Agriculture of P. R. China, 2003). CYA shows good antibacterial activity against Staphylococcus hyicus, Pasteurella multocida, and E. coli (Ding et al., 2006a,b), and also exhibits good growth-promoting effect on broilers and swine. With good clinical safety, CYA has been regarded as a potential replacement of OLA and CBX (Cihak and Srb, 1983).

Only a few studies have investigated the mechanism of antibacterial action of QdNOs. Suter et al. (1978) first found the synthesis of DNA (but not RNA and protein) was completely inhibited by QDX in the absence of oxygen. QdNOs also induced degradation of DNA in both proliferating and nonproliferating cells, while strains were more resistant in the presence of oxygen. QDX was reduced to quinoxaline- $N$-oxide by the intact E. coli cells or the cell-free extract. EPR measurements demonstrated the generation of free radicals during the reduction of QDX. Oxygen or deficiency of energy sources impaired the antibacterial activity and the reduction of QDX. In consistence with Suter's result, our group recently found that CYA also had anaerobe-selective activity, and losing one or two of the oxygen's of CYA exhibited no antibacterial activity (Cheng et al., 2015).

The ability of QDX to cleave DNA was explicitly characterized using in vitro assays by Ganley et al. (2001). The results evidenced that QDX was a hypoxia-selective, redox-activated DNA-cleaving agent. The action of QDX on DNA yielded direct strand breaks with almost no sequence specificity, consistent with the involvement of radical species. In the absence of oxygen, QDX (a) received an electron and a hydrogen ion to form a neutral radical (b) (Figure 2). They considered two possibilities about the DNA-cleaving radical resulting from redox activation of QDX (a). First, the radical $\mathbf{b}$ might directly abstract hydrogen 
<smiles>COC(=O)N/N=C/c1c[n+]([O-])c2ccccc2[n+]1[O-]</smiles>

FIGURE 1 | Chemical structures of veterinary-used QdNO antibacterials.

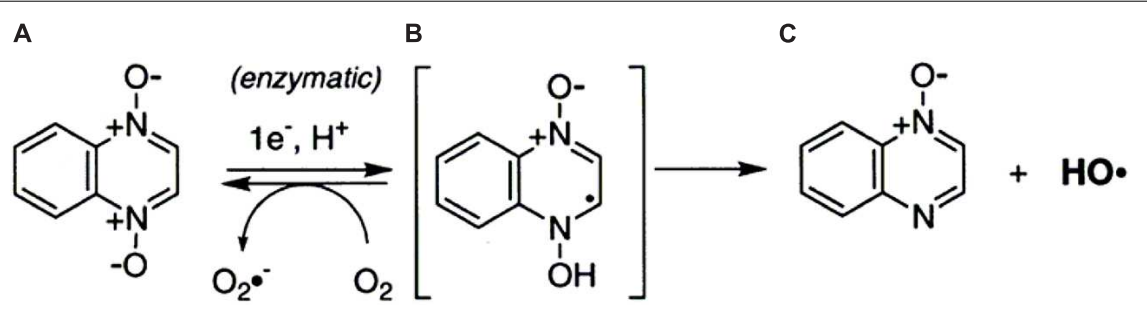

FIGURE 2 | One-electron reduction of quinoxaline 1,4-dioxide by reductase (Ganley et al., 2001).

atoms from the DNA backbone, followed by elimination of water to yield the quinoxaline monoxide (c). Alternatively, radical $\mathbf{b}$ might fragment to form the known DNA-cleaving agent ${ }^{\bullet} \mathrm{OH}$ and monoxide c.

Early study showed that $p o l A, \operatorname{rec} A, \operatorname{rec} B, \operatorname{rec} C$, exrA, and uvrA E. coli mutants were more susceptible to QdNOs than the corresponding repair-proficient strains, while the QdNO reductase activity was demonstrated to be lower in QdNOresistant mutants than in the susceptible parent strain (Suter et al., 1978), indicating that QdNOs were reduced and caused extensive DNA damage in bacterial. Recently, our group investigated the transcriptomic and proteomic profiles of $E$. coli exposed to QdNOs and found that QdNOs mainly induced SOS response and oxidative stress (Cheng et al., 2015). We also confirmed that ROS were induced in the QdNO-treated bacteria and the free radical scavengers attenuated the antibacterial action of QdNOs and DNA damage, suggesting an oxidative-DNAdamage action of QdNOs. The QdNO radical intermediates, likely carbon-centered and aryl-type radicals, as identified by EPR, were the major radicals induced by QdNOs, and xanthine oxidase was identified as one of the QdNO-activating enzymes by using specific enzyme inhibitors (Cheng et al., 2015).

Tirapazamine is a prodrug undergoing clinical trials for various types of cancers (discussed in details in section "Antitumor activity of QdNOs"). Shah et al. (2013) showed that TPZ has antibacterial activity against E. coli, S. aureus, and Clostridium difficile, particularly at low oxygen levels. E. coli mutants deficient in HR were hypersusceptible to TPZ, suggesting that drug toxicity may be due to DNA damage. Moreover, E. coli strains deleted for genes encoding putative reductases were resistant to TPZ, implying that these enzymes are responsible for conversion of the prodrug to a toxic compound.

Though the two $\mathrm{N}$-oxide groups are necessary for the antibacterial activity of QdNOs, some reduced form of quinoxaline compounds were still reported with antibacterial activity (Refaat et al., 2004; Singh et al., 2010, 2011). For example, when the $\mathrm{C}_{2}$ chlorine of 2-Chloro-3-methylquinoxaline was replaced with a benzene ring harboring an aldehyde or a free 
amino group which can be further reacted with aromatic amines and aromatic aldehydes, this compounds also show antimicrobial activity (Singh et al., 2010). Therefore, in addition to the $\mathrm{N}$-oxide group, the side chain of quinoxaline is another determinant of activity.

Hansen et al. (2004) first reported the gene-encoded resistance mechanism to OLA. In their study, two genes of $o q x A$ and $\operatorname{oq} x B$, encoding for proteins homologous to resistance-nodulation-celldivision family efflux systems, were cloned from a conjugative plasmid isolated from E. coli. Plasmids containing the oq $x A B$ genes yielded high resistance to OLA and chloramphenicol in $E$. coli, indicating $o q x A B$ encodes a multidrug efflux pump. Later, they demonstrated the prevalence of the OqxAB efflux pump by horizontal transfer of OLA resistance from OLA-resistant isolates using an OLA-sensitive E. coli as recipient (Hansen et al., 2005). In addition to OLA and chloramphenicol, the OqxAB pump conferred antimicrobial resistance or reduced susceptibility toward a variety of substrates in E. coli, including animal growth promoters, antimicrobials, disinfectants and detergents (Hansen et al., 2007). Interestingly, oqxA gene was not detected in the CYA/OLA- resistant E. coli induced in vitro (Guo et al., 2012), suggesting there are other mechanisms conferring the bacterial resistance.

\section{Antimycobacterial Activity}

Tuberculosis is a common, and in many cases lethal, infectious disease caused by various strains of mycobacteria, usually Mycobacterium tuberculosis. TB has been a companion of mankind since the beginning of human history. In 2010, there where 8.8 million new cases, and 1.5 million deaths, mostly in developing countries (WHO, 2011), where more people contract TB because of compromised immunity due to high rates of AIDS (Lawn and Zumla, 2011). Drug-resistant TB is a public health issue in many developing countries, as treatment of it is longer and requires more expensive drugs. MDR TB is defined as resistance to the two most effective first-line TB drugs, rifampicin and isoniazid. Over the past years, QdNO derivatives as antitubercular drug candidates hold promise in the treatment of TB and its resistant form.

The first publication of QdNO derivatives as antimycobacterium agents dates back to the end of the 1990s by Monge's team (Montoya et al., 1998). Continued identification of novel antitubercular candidates based on their potency ( $\mathrm{MIC}$ to $\mathrm{H}_{37} \mathrm{Rv} M$. $t b$ ), selectivity [SI $=\mathrm{IC}_{50}$ (to VERO cell)/MIC(to $\mathrm{H}_{37} \mathrm{Rv} M$. $t b$ )] and low cytotoxicity make them valid new leads for synthesizing additional analogs with improved antitubercular activity both in vitro and in vivo. A comprehensive review on the properties of QdNO derivatives developed as potential antitubercular agents by Monge's team was reported recently (Vicente et al., 2011). As shown in Figure 3, the QdNO antitubercular compounds can be divided into categories based on their structures, including amide derivatives (1-3), ketone derivatives (4-6), ester derivatives (7-10) and other derivatives (11-12). Compounds 8 and 10, proved efficacious in vivo in a murine model of low dose aerosol infection. Moreover, these two compounds also showed activity against non-replicating bacteria, indicating that QdNOs might lead to shortened therapy, because nonreplicating bacteria is believed to be a major factor responsible for the prolonged nature of antitubercular therapy. Compound 8 is also active on single-drug resistant and MDR clinical isolates.

In the meantime, there were other research groups studying the antimycobacterial activity of QdNOs. As shown in Figure 4, Zanetti's team reported a series of 3-methylquinoxaline 1,4di- $N$-oxide derivatives with a phenylthio, phenylsulfonyl, or phenylsulfinyl linked in R2 position of quinoxaline subunit (Figure 4A). The series of 3-methyl-2-phenyl-thioquinoxaline 1,4-di- $N$-oxide derivatives presented the best MIC data, ranging between 0.39 and $0.78 \mathrm{~g} / \mathrm{mL}$, whereas the oxidation of sulfur bridge to yield phenylsulfinyl and phenylsulfonyl derivatives or its replacement with benzylamino (Figure 4B) or phenylamino group (Figure 4C) slightly reduces its activity (Carta et al., 2002, 2004). Furthermore, $1 \mathrm{mg} / \mathrm{L}$ of 6,7difluoro-3-methyl-2-(3,4-dimethoxyphenylthio) quinoxaline 1,4-dioxide (Figure 4D) exhibited good activity in mouse macrophages infected by $M$. avium paratuberculosis (Zanetti et al., 2005).

Gambino's team has devoted to the synthesis and biological assessment of a large amount of QdNO derivatives complexed with metals, including palladium (Pd; Urquiola et al., 2009) and copper (Cu; Torre et al., 2005; Urquiola et al., 2008) with antitumoral activity, vanadium (Vo) with antitrypanosomal (Urquiola et al., 2006), insulin-mimetic (Noblia et al., 2006), and antitumoral activities (Vieites et al., 2006), and iron (Fe) with antimycobacterial activity (Tarallo et al., 2008, 2010). Two novel iron complexes, $[\mathrm{Fe}(\mathrm{L} 3)(3)]$ (L3: $\mathrm{R} 1=\mathrm{Cl}$, $\mathrm{R} 2=\mathrm{OCH} 3)$ and $[\mathrm{Fe}(\mathrm{L} 4)(3)](\mathrm{L} 4: \mathrm{R} 1=\mathrm{H}, \mathrm{R} 2=\mathrm{CF} 3$; Figure 4E) showed in vitro growth inhibitory activity on $M$. tuberculosis $\mathrm{H}(37) \mathrm{Rv}$ ( $\mathrm{MIC}=0.78 \mu \mathrm{g} / \mathrm{mL}$ ), together with very low unspecific cytotoxicity on murine cell line J774. Both complexes showed higher inhibitory effects on M. tuberculosis than the second-line therapeutic drugs (Tarallo et al., 2010).

Structure-activity relationship suggests that the 1,4-di-Noxide groups in quinoxaline ring are important to increase the antimycobacterial activity (Montoya et al., 1998; Ortega et al., 1999; Sainz et al., 1999). Quinoxaline-2-carbonitrile derivatives has good antimycobacterial activity but appeared to be quite toxic (Ortega et al., 2001, 2002); thus, the replacement of the carbonitrile group with a carboxamide (Zarranz et al., 2003), acetyl, benzoyl (Jaso et al., 2003), or carboxylate groups (Jaso et al., 2005) was proposed. Among the 6(7)substituted quinoxaline-2-carboxylate 1,4-dioxide derivatives, anti-TB activity principally depends on the substituents in the carboxylate group, improving in the following order: benzyl > ethyl > 2-methoxyethyl > allyl > tert-butyl, and the presence of a chloro, methyl, or methoxy group in position 7 of the benzene moiety reduces the MIC and IC(50) values (Jaso et al., 2005). Recently, a research employed 3DQSAR and docking analysis to identify molecular structural features required for effective antimycobacterial activity of quinoxaline-2-carboxamide 1,4-di- $N$-oxide derivatives inside the active site of the Mycobacterium DNA gyrase B subunit, 
<smiles>Cc1c(C(=O)Nc2ccccc2)[n+]([O-])c2ccccc2[n+]1[O-]</smiles>

1

$$
\mathrm{MIC}=3.13 \mu \mathrm{g} / \mathrm{mL}
$$

$\mathrm{SI}>20$

$\mathrm{EC}_{90} / \mathrm{MIC}=0.89$<smiles>CC(=O)c1c(C)[n+]([O-])c2ccccc2[n+]1[O-]</smiles>

4

$$
\begin{aligned}
\mathrm{MIC} & =3.13 \mu \mathrm{g} / \mathrm{mL} \\
\mathrm{SI} & >20 \\
\mathrm{EC}_{90} / \mathrm{MIC} & =0.87
\end{aligned}
$$<smiles>CCOC(=O)c1c(C)[n+]([O-])c2ccccc2[n+]1[O-]</smiles>

7

$$
\begin{aligned}
\mathrm{MIC} & =1.56 \mu \mathrm{g} / \mathrm{mL} \\
\mathrm{SI} & =30.13
\end{aligned}
$$

$\mathrm{EC}_{90} / \mathrm{MIC}=\mathbf{0 . 5 6}$<smiles>Cc1c(C(=O)OCc2ccccc2)[n+]([O-])c2cc(Cl)ccc2[n+]1[O-]</smiles>

10

$$
\begin{aligned}
\mathrm{MIC} & =0.10 \mu \mathrm{g} / \mathrm{mL} \\
\mathrm{SI} & =76.9
\end{aligned}
$$

$\mathrm{EC}_{90} / \mathrm{MIC}=0.01$<smiles>Cc1ccccc1NC(=O)c1c(C)[n+]([O-])c2ccccc2[n+]1[O-]</smiles>

2

$$
\begin{aligned}
\mathrm{MIC} & =6.25 \mu \mathrm{g} / \mathrm{mL} \\
\mathrm{SI} & >10 \\
\mathrm{EC}_{90} / \mathrm{MIC} & =0.42
\end{aligned}
$$<smiles>CC(=O)c1c(C)[n+]([O-])c2ccc(F)cc2[n+]1[O-]</smiles>

5

MIC $=3.13 \mu \mathrm{g} / \mathrm{mL}$

$\mathrm{SI}>20$

$\mathrm{EC}_{90} / \mathrm{MIC}=0.79$<smiles>CCOC(=O)c1c(C)[n+]([O-])c2ccc(Cl)cc2[n+]1[O-]</smiles>

8

$\mathrm{MIC}=0.20 \mu \mathrm{g} / \mathrm{mL}$

$\mathrm{SI}>50$

$\mathrm{EC}_{90} / \mathrm{MIC}=2.30$<smiles>[Y]c1ccc2c(c1)[n+]([O-])c(C#N)c(-c1ccc([Al])cc1)[n+]2[O-]</smiles>

11

MIC $<0.20 \mu \mathrm{g} / \mathrm{mL}$

$\mathrm{SI}>124$<smiles>Cc1ccccc1NC(=O)c1c(C)[n+]([O-])c2ccc(Cl)cc2[n+]1[O-]</smiles>

3

MIC $=6.25 \mu \mathrm{g} / \mathrm{mL}$

$\mathrm{SI}>10$

$\mathrm{EC}_{90} / \mathrm{MIC}=\mathbf{0 . 1 4}$<smiles>CC(=O)c1c(C)[n+]([O-])c2ccc(Cl)cc2[n+]1[O-]</smiles>

6

$$
\begin{aligned}
\mathrm{MIC} & =0.78 \mu \mathrm{g} / \mathrm{mL} \\
\mathrm{SI} & >10 \\
\mathrm{EC}_{90} / \mathrm{MIC} & =3.13
\end{aligned}
$$<smiles>Cc1c(C(=O)OCc2ccccc2)[n+]([O-])c2ccccc2[n+]1[O-]</smiles>

$$
\begin{aligned}
\mathrm{MIC} & =0.10 \mu \mathrm{g} / \mathrm{mL} \\
\mathrm{SI} & =470 \\
\mathrm{EC}_{90} / \mathrm{MIC} & =1.50
\end{aligned}
$$<smiles>[Y1]c1ccc(C(=[W])Nc2c(C)[n+]([O-])c3cc([R])c([R])cc3[n+]2[O-])cc1</smiles>

12

$$
\mathrm{MIC}<0.20 \mu \mathrm{g} / \mathrm{mL}
$$

$\mathrm{SI}>153$ 


\section{A}

$\mathrm{n}=0,1,2$<smiles></smiles>

C<smiles>Cc1c(NCc2ccccc2)[n+]([O-])c2cc(F)c(F)cc2[n+]1[O-]</smiles>

B<smiles>[R3]c1cc(Nc2c(C)[n+]([O-])c3cc(F)c(F)cc3[n+]2[O-])cc([R])c1[R]</smiles>

D<smiles>COc1ccc(Sc2c(C)[n+]([O-])c3cc(F)c(F)cc3[n+]2[O-])cc1OC</smiles>

E

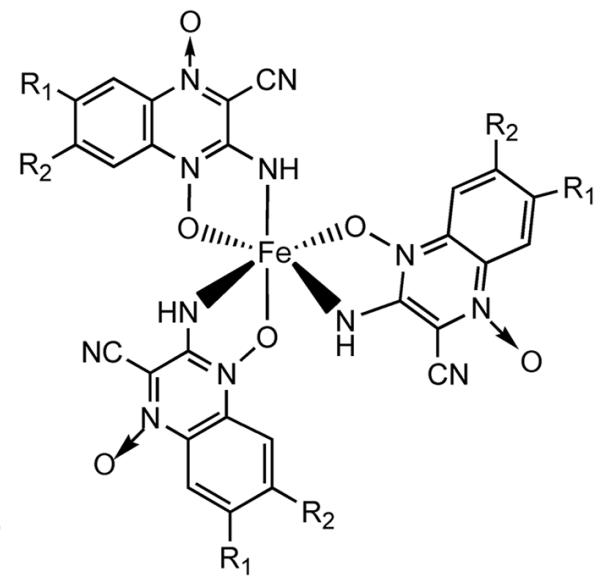

FIGURE 4 | General structures of QdNOs with antimycobacterial activity published by Zanetti's (A-D) and Gambino's teams (E).

and the obtained binding mode was as same as that of the novobiocin X-ray structure (Radwan and Abdel-Mageed, 2014).

\section{Antifungal Activity}

Candida is a genus of yeasts, some of which can cause disease, for example, Candida albicans cause infections (candidiasis or thrush) in humans and other animals. In healthy individuals, these infections can be cured with topical or systemic antifungal medications (commonly over-the-counter treatments like miconazole or clotrimazole), while in debilitated or immunocompromised patients, candidiasis may become a systemic disease.

Carta et al. (2002, 2004) reported the in vitro anticandida activity (against C. albicans, C. glabrata, C. krusei, and C. parapsilosis clinical isolates) of 3-methylquinoxaline 1,4-dioxide derivatives, in particular 2,7-dichloro-3-methylquinoxaline 1,4-dioxide (Figure 5A) and 2-chloro-7-ethoxy6-fluoro-3-methylquinoxaline 1,4-dioxide were the most active against C. Krusei, exhibiting MICs of 0.4 and $1.9 \mathrm{~g} / \mathrm{mL}$, respectively (miconazole $\mathrm{MIC}=0.9 \mathrm{~g} / \mathrm{mL}$ ). Murthy et alreported one of the 2,3-diphenyl quinoxaline 1,4-dioxide derivatives (Figure 5B) as a fruitful matrix for further biological evaluation based on its wide zones of inhibition against $C$. albicans and S. cerevisiae (Murthy et al., 2011).<smiles>Cc1c(Cl)[n+]([O-])c2cc(Cl)ccc2[n+]1[O-]</smiles><smiles>COc1ccc2c(c1)[n+]([O-])c(-c1ccccc1)c(-c1ccccc1)[n+]2[O-]</smiles>

FIGURE 5 | General structures of QdNOs with antifungal activity.

\section{ANTITUMOR ACTIVITY OF QdNOs}

It has been recognized for more than 50 years that very low levels of oxygenation (hypoxia) protect cells from killing by $\mathrm{X}$-irradiation. Hypoxic cells, which are resistant to radiotherapy, are present in solid tumors but not in normal tissues, therefore become a major problem for radiation therapy of tumors. Additionally, hypoxic cells are non-proliferating which do not respond to drugs active against only proliferating cells, and are distant from the blood vessels carrying the drug. Thus the development of drugs with selective toxicity toward hypoxic cells is a key objective in anticancer chemotherapy. The recent development of QdNOs that are non-toxic until they are activated in the hypoxic cell opens a new era.

Tirapazamine (Zeman et al., 1986) (Figure 6A), which actually belongs to BTOs, is the first drug that has been shown to be an efficient and selective cytotoxin for hypoxic cells. TPZ has been subjected to phase II testing in patients with head, neck, and gynecological cancers (Covens et al., 2006; Maluf et al., 2006; Cohen et al., 2007).

In addition to TPZ, many research teams have been devoted to the synthesis and development of QdNO antitumoral drugs. Monge et al. (1995b) synthesized a series of 3-aminoquinoxaline2-carbonitrile 1,4-di- $N$-oxides (Figure 6B) with a range of electron-donating and -withdrawing substituents in the 6and/or 7- positions and evaluated for toxicity to hypoxic cells. As the electron-withdrawing nature of the 6(7)-substituent increases, the reduction potential becomes more positive and the compound is more readily reduced. The most potent cytotoxins were the 6,7-dichloro and 6,7-difluoro derivatives, which were 30 -fold more potent than TPZ. The compound 7 (4-nitrophenyl)-2-quinoxalinecarbonitrile 1,4-di- $N$-oxide (Figure 6C) is 150-fold more potent than TPZ, demonstrating that the amino group in three position is not necessary for activity (Monge et al., 1995a). Meanwhile, they developed two derivatives bearing a basic side chain. The 7-choloro- 


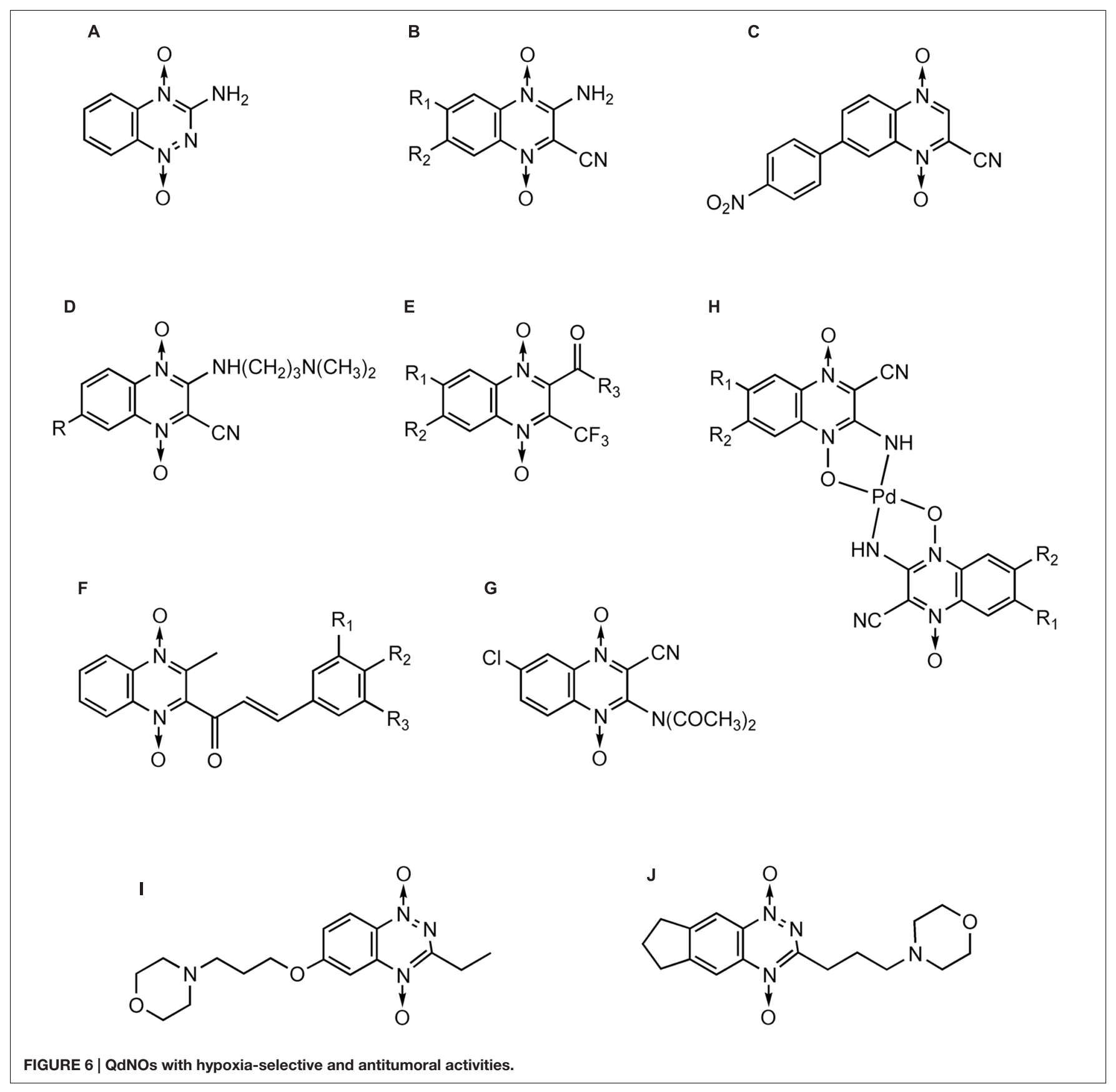

and 7-trifluoromethyl 3-(dimethylaminopropyl) amino-2quinoxalinecarbonitrile 1,4-dioxide (Figure 6D) showed high potency and excellent selectivity (Monge et al., 1995a). They further studied the activity of the basic chain in 3 position of the 2-quinoxalinecarbonitrile 1,4-dioxides and showed that the replacement of ( $N, N$-dialkyl amino) alkyl amino chain with aromatic rigid moieties (anilines and arylpiperazines) in three position held the potency but reduced the hypoxia-selectivity (Ortega et al., 2000). Continuingly, they synthesized a new series of 2-alkylcarbonyl and 2-benzoyl-3-trifluoromethylquinoxaline 1,4-di- $N$-oxide (Figure 6E) and evaluated for in vitro antitumor activity against MCF7 (breast), NCI-H460 (lung), and SF-268 (central nervous system) cells. In general, anticancer activity depends on the substituents in the carbonyl group, improving in the order: ethyl < isopropyl < tert-butyl < phenyl-ones (Zarranz et al., 2004). By comparison of the ${ }^{1} \mathrm{H}$ NMR spectra, Solano et al. (2007) also showed that the best activity was observed in derivatives with electron-withdrawing groups in position 6 or 7 on the quinoxaline ring whereas loss of one or two oxygens reduced the cytotoxicity.

Besides Monge's team, Das et al. (2009) reported a series of 2-(3-aryl-2-propenoyl)-3-methylquinoxaline-1,4-dioxides (Figure 6F) could reverse the MDR properties of murine L-5178Y leukemic cells which were transfected with the human 
MDR1 gene. Ismail et al. (2010) evaluated antitumor activity of a new series of QdNOs against liver carcinoma (Hepg2) and brain tumor (U251) human cell line, and compound 4 (Figure 6G) was the most potent hypoxia selective-cytotoxin on EAC cell line (Ismail et al., 2010). Urquiola et al. (2009) synthesized four new palladium(II) complexes with the formula $\operatorname{Pd}(\mathrm{L})(2)$ (Figure 6H), where $\mathrm{L}$ were quinoxaline-2-carbonitrile 1,4-di- $N$-oxide derivatives, and evaluated their cytotoxicity on V79 cells. $\operatorname{Pd}(\mathrm{L} 1)(2)$ and $\operatorname{Pd}(\mathrm{L} 2)(2)$, where $\mathrm{L} 1$ was 3aminoquinoxaline-2-carbonitrile 1,4-di- $N$-oxide and L2 was 3-amino-6(7)-methylquinoxaline-2-carbonitrile 1,4-di- $\mathrm{N}$-oxide, showed non-selective cytotoxicity. $\mathrm{Pd}(\mathrm{L} 3)(2)$, where L3 was 3-amino-6(7)-chloroquinoxaline-2-carbonitrile 1,4-di- $\mathrm{N}$-oxide, resulted in vitro more potent cytotoxin in hypoxia than the corresponding free ligand and TPZ. Pd(L2)(2) introduced a scission event in supercoiled DNA, yielding the circular relaxed form. Meanwhile, both $\mathrm{Pd}(\mathrm{L} 1)(2)$ and $\mathrm{Pd}(\mathrm{L} 3)(2)$ produced the loss of negative supercoils, rendering a family of topoisomers with reduced electrophoretic mobility. For the highest doses assayed, $\mathrm{Pd}(\mathrm{L} 3)(2)$ was even able to introduce positive supercoils on the plasmid DNA (Urquiola et al., 2009).

Although TPZ has attractive features of targeting hypoxic cells in tumors, it has limited clinical activity, in part because of poor extravascular penetration. Hicks et al. (2010) used a spatially resolved pharmacokinetic/pharmacodynamic model to guide the progression of $281 \mathrm{TPZ}$ analogs through a hierarchical screen. SN29751 (Figure 6I) and SN30000 (Figure 6J) were identified as the most promising hypoxic cytotoxins, and SN30000, in particular, showed higher hypoxic potency and selectivity than TPZ in tumor cell cultures and faster diffusion through HT29 and SiHa multicellular layers.

\section{QdNO-Induced Radicals}

The mode of action of QdNO antitumoral drugs was most comprehensively studied in TPZ. As shown in Figure 7, it is known that TPZ (1) is an excellent substrate for a variety of intracellular reductases that add an electron to the drug to form an radical anion (2) (Brown, 1999), which then receives a proton to form a neutral radical (3). This neutral radical itself or produces other active radicals to abstract hydrogen from DNA, producing both SSBs and DSBs, resulting in chromosome breaks (Wang et al., 1992). Under aerobic conditions, oxygen can remove the additional electron from the radical anion (2), thereby back-oxidizing it to the non-toxic parent with a concomitant production of $\mathrm{O}_{2}^{\circ-}$ (Lloyd et al., 1991). Thus, the differential hypoxic cytotoxicity results from the fact that the TPZ radical is much more cytotoxic than the $\mathrm{O}_{2}^{\bullet-}$.

There have been a number of suggestions about the identity of active radicals produced by TPZ. An early proposal was that the ${ }^{\bullet} \mathrm{OH}$ radical was released from the protonated anion (3), and the monoxide of TPZ (4) was produced simultaneously (Laderoute and Rauth, 1986), but this was later rejected in favor of the protonated radical anion itself as being the active species (Laderoute et al., 1988). Release of an ${ }^{\bullet} \mathrm{OH}$ radical has been favored by other research workers, based on the similarity in the spectrum of products arising from TPZ-mediated damage to both purine and pyrimidine bases and deoxyribose sugars when compared with damage arising from the $\bullet^{\bullet} \mathrm{OH}$ radical, although TPZ-mediated damage exhibited some preference for purine over pyrimidine damage (Kotandeniya et al., 2002; Birincioglu et al., 2003; Chowdhury et al., 2007). Additionally, an EPR study using DMPO as a spin trap reported a composite spectrum of both a Ccentered and an $\mathrm{OH}$-adduct, DMPO-OH (Patterson and Taiwo, 2000), supporting evidence for the release of an ${ }^{\bullet} \mathrm{OH}$ radical.

In contrast, Shinde et al. $(2009,2010)$ could not find any evidence that ${ }^{\bullet} \mathrm{OH}$ is eliminated from TPZ following enzymatic reduction. They presented that the protonated radical anion (3) undergoes dehydration to the BTZ (5) (Shinde et al., 2009), causing oxidative damage to DNA and to oxidize TPZ itself (Anderson et al., 2003a,b, 2006). In situ EPR measurement confirmed that a multi $\mathrm{N}$-centered radical, consistent with the BTZ radical (5), was formed (Shinde et al., 2009). Similarly, the one electron reduction potentials $[\mathrm{E}(1) \mathrm{R}]$ of the BTZ radicals (5) also tracked the hypoxic cytotoxicity to human tumor cells in a series of BTO analogs of TPZ (3-amino BTO; Anderson et al., 2005). However, although the E(1)R value for the BTZ radical (5) of TPZ, $1.31 \mathrm{~V}$ (Anderson et al., 2003b), is sufficient to oxidize the purine bases of DNA, but not to directly oxidize the pyrimidine bases of DNA. Later, they trapped TPZ and a series of 3-substituted analogs by $N$-tert-butyl- $R$-phenylnitrone and observed by EPR the formation of their aryl (phenyl) radicals (6), which is stronger oxidants than the BTZ radical (5) (Shinde et al., 2010).

There are still some questions whether protonated radical anion (3) will undergo $\mathrm{N}-\mathrm{OH}$ homolysis to its monoxide (4) and - $\mathrm{OH}$, or alternatively, radical anion (2) may react by dehydration and form aminyl radicals (5) and $\mathrm{H}_{2} \mathrm{O}$ or phenyl radicals (6) and $\mathrm{H}_{2} \mathrm{O}$. Recently, Yin et al. (2012) discovered that dehydration might be the result of a two-step sequence that involved $\mathrm{N}-\mathrm{OH}$ homolysis and formation of ${ }^{\bullet} \mathrm{OH}$ aggregates of the monoxide (4) followed by $\mathrm{H}$-abstraction within the ${ }^{\bullet} \mathrm{OH}$ aggregates to form hydrates of aminyl (5) or of phenyl (6) radicals (Figure 7, dashed arrows).

Electron paramagnetic resonance experiments indicate both an aryl-type radical and an oxidizing radical, trapped as a carbon-centered radical, are formed from the protonated radical anion of the bioreductive anticancer prodrug, SN30000 (Anderson et al., 2014). The carbon-centered radical, produced upon the one-electron oxidation of the 2-electron reduced metabolite of SN30000, oxidizes 2deoxyribose, leads to double strand breaks. Hunter et al. (2014a) found hypoxia-activated prodrugs of DNA-damaging cytotoxins (TPZ, SN30000) might inhibit growth of triplenegative breast cancer (TNBC) by simultaneously addressing the two targets, tumor hypoxia and derangement of $\mathrm{HR}$ repair.

Recently, Yadav et al. (2014) found The ${ }^{\bullet} \mathrm{OH}$ radical was released from 3-trifluoromethyl-quinoxaline 1,4-dioxides upon one-electron reduction by cytochrome P450 oxidoreductase. This process effectively competes with back oxidation of the intermediate radical anion by oxygen and underlies the increased aerobic cytotoxicity of such compounds compared to that seen for, TPZ. 


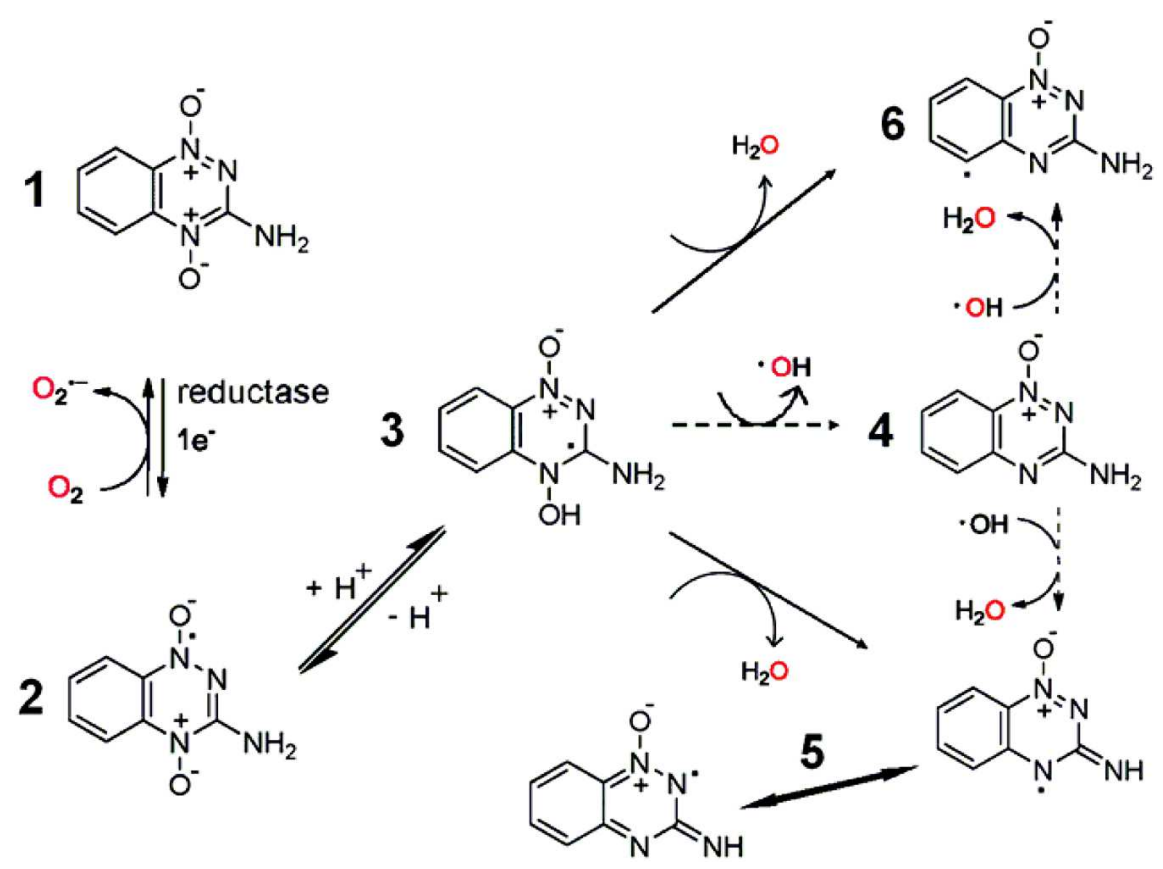

FIGURE 7 | Bioreduction of TPZ with produced free radicals based on Shinde et al. (2010) and Yin et al. (2012).

\section{Reductase}

Another major unresolved question is the identity of the enzyme(s) that activates a QdNO to cause cell death. Numerous enzymes, including xanthine oxidase (EC 1.2.3.1; Laderoute et al., 1988), cytochrome P450 (Wang et al., 1993), DT-diaphorase (EC 1.6.99.2; Patterson et al., 1994), and NADPH:cytochrome P450 reductase (EC 1.6.2.4; Patterson et al., 1995), are able to metabolize TPZ in vitro under hypoxic conditions. A correlation between NADPH:cytochrome P450 reductase level (Patterson et al., 1997) or NOS (Chinje et al., 2003) level and sensitivity to TPZ has been reported. For a long time, there was no agreement as to which enzyme(s) are involved in the DNA damage until Evans et al. (1998) showed that TPZ was metabolized to DNA-damaging radicals by intranuclear enzymes. TPZ radicals formed outside nuclei do not contribute to intranuclear DNA damage, and the $80 \%$ of the drug metabolism that occurs in the cytoplasm is probably irrelevant for hypoxic killing effect of this drug. Later, Delahoussaye et al. (2001) demonstrated that multiple reductases in the nuclear matrix metabolized TPZ under hypoxia. DNA SSBs were probably caused by the most abundant source of reductase in the nucleus, while DNA DSBs were formed by an unknown nuclear reductase requiring only NADPH for its activity.

Hunter et al. (2014b) observed that forced expression of FAD-dependent oxidoreductase domain containing 2 (FOXRED2) increased activation of hypoxia-targeted prodrugs TPZ and SN30000. They also identified the flavoprotein P450 (cytochrome) oxidoreductase, which is responsible for prodrug activation during hypoxia, as the predominant determinant of sensitivity to SN30000 (Hunter et al., 2015).

\section{Topoisomerase and Polymerase $\beta$}

Topoisomerase II is essential in mammalian cells, because it resolves the unfavorable topological structures in DNA during replication and transcription. Drugs that stabilize Topo II with a DNA DSB to form cleavable complex are termed Topo II poisons (Pommier et al., 2010). Since TPZ produces a marked inhibition of DNA replication in the nuclear matrix (Peters et al., 2001), and TPZ-induced DNA DSBs are protein-associated (Olive, 1995; Siim et al., 1996), Peters and Brown (2002) considered TPZ might poison Topo II. They found under hypoxic conditions, the nuclear extracts from LXFL 529 human lung carcinoma cells treated with TPZ reduced the activity of Topo II. Inhibitors of the Topo II catalytic cycle abrogated TPZgenerated DNA DSBs and cytotoxicity, and TPZ stabilized DNA Topo II cleavable complexes (Peters and Brown, 2002). Using Saccharomyces cerevisiae as a model, overexpression of TOP2 (encoding Topo II) leads to hypersensitivity to TPZ, suggesting that Topo II is also a target of TPZ in yeast (Hellauer et al., 2005). XK469 (NSC 697887) and CQS (NSC 339004), two synthetic quinoxaline derivatives without two oxygens on the quinoxaline ring, also show solid tumor selectivity. XK469 and CQS have entered Phase I and Phase II clinical study, respectively (Miller et al., 1997; Bekaii-Saab et al., 2006; Alousi et al., 2007). Gao et al. (1999) reported the primary target of XK469 is Topo II $\beta$, and CQS was found to be both a Topo-II $\alpha$ and a Topo-II $\beta$ poison (Gao et al., 2000). The large aromatic side chains of XK469 and CQS can not be ignored to the drug action. Except for TopII, TPZ also induces other DNA-protein cross-links, including DNA-Topo I cleavable complexes (Evans et al., 2008) and DNA-Pol $\beta$ cross-link with the lesion (Sung and Demple, 2006). 
Evans et al. (2008) further showed an overall model of TPZ damage in which DNA SSBs, base damage, and DNAprotein cross-links (including Topo I and II cleavable complexes) produced stalling and collapse of replication forks. The resolution of the complex required HR and XPF/ERCC1 protein for their repair. Cells defective in HR proteins were particularly sensitive to TPZ, and extensive sister chromatid exchanges occurred after treatment with TPZ. In addition, TPZ preferentially kills mutants both with defects in XPF/ERCC1 and base excision repair. $\mathrm{H} 2 \mathrm{AX}$, an indicator of DNA DSBs, is induced preferentially in cells in the $S$ phase of the cell cycle.

In a dose-dependent fashion, polymerase $\beta$ DNA-protein cross-links (Pol $\beta$-DPC) were detected in MDA-MB-231 human cells treated with the antitumor drug TPZ (much more Pol $\beta$-DPC under $1 \% \mathrm{O}_{2}$ than under $21 \% \mathrm{O}_{2}$; Quinones et al., 2015). Mouse embryonic fibroblasts challenged with TPZ also incurred Pol $\beta$-DPC.

\section{Hypoxia-Inducible Factor 1}

Hypoxia-inducible factor 1 , a heterodimeric transcription factor that mediates the adaptation of tumor cells and tissues to the hypoxic environment, has attracted considerable interest as a potential therapeutic target. The subunit $1 \alpha$ of HIF plays an essential role in the transcriptional activation of genes involved in tumor angiogenesis invasiveness and metastasis with its downstream target, VEGF (Carmeliet et al., 1998).

Quinoxaline 1,4-di- $N$-oxides could reduce the expression of HIF-1 $\alpha$ mRNA in T-84 cells, and 2-benzoyl-3-phenyl6,7-dichloroquinoxaline 1,4-dioxide (DCQ) is shown most effective in decreasing the HIF- $1 \alpha \mathrm{mRNA}$ and protein levels (Diab-Assef et al., 2002). A hypoxic cytotoxin, 3-amino2-quinoxalinecarbonitrile 1,4-dioxide (TX-402), which is an improved analog of TPZ, has been shown to inhibit HIF- $1 \alpha$ expression (Nagasawa et al., 2003). Recently, it is found that TPZ acts in a novel manner to inhibit HIF- $1 \alpha$ accumulation, in which HIF- $1 \alpha$ translational regulation is involving, dependent on the phosphorylation of translation initiation factor $2 \mathrm{a}$ (eIF2a; Zhang et al., 2010).

Weng et al. (2011) showed that suppression of HIF- $1 \alpha$ by 3-(4-Bromophenyl)-2-(ethylsulfonyl)-6-methylquinoxaline 1,4-dioxide (Q39) resulted in a drastic decrease in VEGF expression. Unlike TPZ, suppression of HIF$1 \alpha$ accumulation by Q39 correlated with prominent dephosphorylation of mTOR (mammalian target of rapamycin) and initiation factor $4 \mathrm{E}$-binding protein 1 at the translational level. 3-[2-hydroxyethyl(methyl)amino]-2quinoxalinecarbonitrile 1,4-dioxide (TX-2098) was also shown to have antitumor effect in pancreatic cancer, through inhibiting VEGF and HIF-1 $\alpha$ targeted gene expression (Miyake et al., 2012). Recently, it is demonstrated that DCQ blocks breast cancer metastasis by targeting the HIF-1 pathway (Ghattass et al., 2014). Cancer cell death was associated with an increase in ROS independently of p53 and was inhibited by antioxidants. DCQ-induced ROS was associated with DNA damage, the downregulation of HIF- $1 \alpha$, and inhibition of VEGF secretion. In MCF-7 (p53 wildtype), HIF-1 $\alpha$ inhibition was partially via p53-activation and was accompanied by a decrease in p-mTOR protein, suggesting interference with HIF-1 $\alpha$ translation. In MDA-MB-231 (p53 mutant), DCQ reduced HIF-1 $\alpha$ through proteasomal-dependent degradation mechanisms.

Combinational use of TPZ with other inhibitors represents a novel mechanism for targeting tumor. In combination with TPZ, topoisomerase I inhibitors exhibited synergistic cytotoxicity and induced significant apoptosis in several hepatocellular carcinoma cell lines (Cai et al., 2014). The enhanced apoptosis induced by TPZ plus SN-38 (the active metabolite of irinotecan) was accompanied by increased mitochondrial depolarization and caspase pathway activation. The combination treatment dramatically inhibited the accumulation of HIF- $1 \alpha$ protein, decreased the HIF-1 $\alpha$ transcriptional activation, and impaired the phosphorylation of proteins involved in the HR repair pathway, ultimately resulting in the synergism of these two drugs. TPZ mediates central vascular dysfunction in tumors and is also a competitive inhibitor of NOS. Baker et al. (2013) further investigated the vascular-targeting activity of TPZ by combining it with NOS inhibitor L-NNA, or with low oxygen content gas breathing. Irreversible loss of perfusion and enhanced tumor cell death was observed when TPZ was combined with either low oxygen or a NOS inhibitor, illustrating a novel use of hypoxiaactivated cytotoxic prodrugs as vascular targeting agents.

\section{ANTIPROTOZOAL ACTIVITIES OF QdNOs}

\section{Antitrypanosomal Activity}

Trypanosoma cruzi is the haemoflagellate protozoan that causes the Human American trypanosomiasis, or Chagas disease, representing a relevant health problem in Central and South America. The acute form of Chagas disease usually goes unnoticed and may present as a localized swelling at the site of entry. The chronic form may develop 10 to 20 years after infection, which affects internal organs (e.g., the heart, the esophagus, the colon, and the peripheral nervous system), sometimes causing death to affected people from heart failure. The first line of treatment is nifurtimox and benznidazole.

Cerecetto's team (Cerecetto et al., 1999) firstly noticed QdNO derivatives had antitrypanosomal activity against epimastigote forms of $T$. cruzi. They reported a vanadium complexe of QdNO, [V(IV)O(L)(2)], where L were 3-aminoquinoxaline-2carbonitrile 1,4-di- $N$-oxide derivatives (Figure 8A), was provide with excellent antitrypanosomal activity, similar to that of the reference drugs nifurtimox and benznidazole and higher than that of the corresponding free ligands. The antitrypanosomal activity of these vanadium complexes could be explained on the basis of their lipophilicity and the electronic characteristics of the quinoxaline substituents (Urquiola et al., 2006). They also reported two QdNO compound, R3 = methyl $(\mathrm{SI}>53.3$, selectivity index $=\operatorname{ID}_{50}$ (macrophage) $/ \operatorname{ID}_{50}(T$. cruzi) $)$ and R3 = phenyl (SI > 33.3; Figure 8B), displayed excellent parasite/mammal selectivity indexes. Those compounds are able to accumulate squalene suggesting that anti-T. cruzi mechanism of action is not involved the inhibition of sterol biosynthesis (Gerpe et al., 2010). 
<smiles>[R]C(=O)Nc1c(C)[n+](O)c2cc(Cl)ccc2[n+]1[O-]</smiles>

Monge's team also found that QdNO derivatives presented good inhibitor activity to the growth of $T$. cruzi in in vitro assays, among which a QdNO derivative (Figure $8 \mathrm{C}$ ) were the most cytotoxic compounds against the protozoan, and the $\mathrm{IC}_{50}$ were of the same order of that of nifurtimox (Aguirre et al., 2004). The authors reported some SAR deductions: the presence of a halo-substituent (electron-withdrawing) at benzene moiety of quinoxaline produces more active compounds; more hydrophilic compounds decrease the antitrypanosomal activity; a reductive metabolism could be implicated in the mechanism of action. Later, they prepared a series of heterocyclic-2-carboxylic acid (3-cyano-1,4-di- $\mathrm{N}$-oxidequinoxalin-2-yl)amide derivatives (Figure 8D), among which compounds $(\mathrm{R} 6=\mathrm{F}, \mathrm{R} 7=\mathrm{F}, \mathrm{X}=\mathrm{O})$ and $(\mathrm{R} 6=\mathrm{F}, \mathrm{R} 7=\mathrm{F}, \mathrm{X}=\mathrm{S}$; Figure $\mathbf{8 D})$ presented $\mathrm{IC}_{50}$ values in the same order as nifurtimox (Ancizu et al., 2009). Recently, they synthesized a series of 3-trifluoromethyl QdNOs, among which derivatives possessing electron-withdrawing substituents in the 2-, 3-, 6-, and 7-positions were the most active compounds (Benitez et al., 2011). One 3-trifluoromethyl QdNO compound (Figure 8E), which was substituted with fluoro groups at the 6- and 7-positions of the quinoxaline ring, was the most active $\left(\mathrm{IC}_{50}=0.4 \mu \mathrm{M}\right)$ and selective $(S I=10)$ in the cytotoxicity assay (Torres et al., 2013). It is demonstrated that inhibition of mitochondrial dehydrogenases are involved in the anti-T. cruzi activity of the most active derivatives (Benitez et al., 2011; Torres et al., 2013). 
Leishmaniasis is a parasitic disease which appears in visceral, cutaneous and mucocutaneous forms affecting millions of people throughout the world. Monge's team tested pyrazole quinoxaline derivatives against Leishmania peruviana. 2,6-dimethyl-3-fquinoxaline 1,4-dioxide (Figure $\mathbf{8 F}$ ) was the most active compound of this series against $L$. peruviana $\left(\mathrm{IC}_{50}=8.9 \mu \mathrm{M}\right.$; Estevez et al., 2011). This compound resulted non-toxic for Vero and LLc-Mk2 cells, and was almost 6 to 13 times more active on Leishmania than on THP-1 or MPM. According to the study of Barea et al. (2012), piperazine linked QdNO (Figure 8G) emerged as the best leishmanicidal agent against L. infantum $\left(\mathrm{IC}_{50}=5.7 \mu \mathrm{M}\right)$. Their later study indicated that the $\mathrm{R}=$ cyclohexyl derivative (Figure $\mathbf{8 H}$ ) had the best antileishmanial activity against $L$. infantum $\left(\mathrm{IC}_{50}=2.5 \mu \mathrm{M}\right)$ while the $\mathrm{R}=3$-chloropropyl derivative (Figure $\mathbf{8 H}$ ) was the best against $L$. amazonensis ( $\mathrm{IC}_{50}=0.7 \mu \mathrm{M}$; Barea et al., 2013). Villalobos-Rocha et al. (2014) evaluated the in vitro biological activity of 33 ethyl and methyl quinoxaline-7-carboxylate 1,4di-N-oxide derivatives on $T$. cruzi and L. mexicana, of which M7 (Figure 8I) and E4 (Figure 8J) displayed activity against both parasites. Compound M2 (Figure 8K) was predicted in the docking procedure as a potential T. cruzi trypanothione reductase inhibitor by its interaction with five residues close to the active site of the enzyme.

\section{Antimalarial Activity}

Plasmodium falciparum is one of the species of Plasmodium that cause malaria in humans. Malaria caused by this species is the most dangerous form of malaria, with the highest rates of complications and mortality. For nearly half a century, chloroquine has been the primary therapy of choice. However, chloroquine-resistant P. falciparum is now observed in nearly all of the malaria-endemic regions and causes the most deadly form of malaria. Therefore, it is necessary to develop cheaper and more effective drugs against the parasite.

Zarranz et al. (2005) synthesized new series of 3arylquinoxaline- carbonitrile derivatives (Figure 9A) and tested for their in vitro and in vivo activity against the erythrocytic development of $P$. falciparum with different chloroquineresistance status. These series showed superior antimalarial activity in respect to reduced quinoxaline analogs. The best activity was observed with non-substituted QdNOs in positions 6 and 7 of the aromatic ring and with a hydrogen or chloro substituent in para position of the phenyl group (Figure 9A). Vicente et al. (2008) identified new compounds structurally based on 3-phenyl-quinoxaline-2-carbonitrile 1,4-di- $N$-oxide derivatives (Figure 9B) active against $P$. falciparum. Derivative 1 (Figure 9B, $\mathrm{X}=\mathrm{O}, \mathrm{R} 7=\mathrm{H}$ ) demonstrated high potency $[\mathrm{IC}(50)=0.63 \mathrm{mM}]$ and good selectivity $(S I=10.35)$, thereby becoming a new lead-compound. Marin et al. (2008) synthesized derivatives of 3-trifluoromethyl-2-arylcarbonylquinoxaline 1,4-di- $N$-oxide (Figure 9C) and evaluated for their capacity to inhibit the growth of chloroquine-resistant P. falciparum FCB1 strain in culture. Compound 7-chloro-2-(2-furylcarbonyl)3-trifluoromethyl-1,4-quinoxaline di- $\mathrm{N}$-oxide (Figure 8C, $\mathrm{Ar}=2$-Furyl, $\mathrm{R} 1 / \mathrm{R} 2=\mathrm{Cl} / \mathrm{H}$ ) was the most active, being almost five times more active than chloroquine. It was also 50 times more active against $P$. falciparum than toxic toward MCF7 cells. SAR showed that bioisosteric modification of phenyl group by 2-thienyl or 2-furyl subunits, R2 position must be free or occupied by a methyl group and $\mathrm{R} 1$ position must be free or occupied by $\mathrm{Cl}, \mathrm{CH}_{3}, \mathrm{OCH}_{3}$ or $\mathrm{CF}_{3}$. Barea et al. (2011) synthesized new 3-amino-1,4-di- $N$-oxide quinoxaline2-carbonitrile derivatives as acetoxybenzamides (Figure 9D) and sulfonamides (Figure 9E), and evaluated for their in vitro antimalarial and antileishmanial activity. Compounds with one halogenous group substituted in position 6 and 7 provide an efficient approach for further development of antimalarial and antileishmanial agents. From a series of quinoxaline analogs of chalcones in another study, compounds $1 \mathrm{a}\left(\mathrm{IC}_{50}=6.2 \mu \mathrm{M}\right.$; Figure 9F) and $2 \mathrm{a}\left(\mathrm{IC}_{50}=5.8 \mu \mathrm{M}\right.$; Figure 9G) were the most active against FCR-3 P. falciparum (Gil et al., 2014). SAR demonstrated the importance of an enone moiety linked to the quinoxaline ring in the search for antimalarial ligands.

The intracellular mechanism of the antiparasitic action of QdNOs is barely elucidated. Recently, Brizuela et al. (2014) shows that one QdNO-derived compound, Conoidin A [2,3-bis(bromomethyl)-1,4-dioxide-quinoxaline] (Figure 9H), exhibites potent lytic activity against $P$. falciparum and constitutes an irreversible Peroxiredoxin-2 (Prx2) inhibitor. Conoidin A is first shown as an inhibitor of host cell invasion by the human pathogen T. gondii (Carey et al., 2004), and this compound is a covalent inhibitor of $T$. gondii peroxiredoxin II (Haraldsen et al., 2009). Conoidin A can also inactivate the peroxiredoxin-1 from the human hookworm Ancylostoma ceylanicum by alkylating or crosslinking the catalytic cysteines, while maintaining the enzyme in the "locally unfolded" conformation (Nguyen et al., 2013). Peroxiredoxin, a thioldependent peroxidase, serves a critical role in converting ROS signals into a cellular response. When Plasmodium sp. invades red cells, it imports Prx2 from the host cell to the parasite cytosol during intraerythrocytic development in an attempt to make up for degradation of peroxides generated during cell metabolism. Therefore, treatment of erythrocytes with Conoidin A produces an unviable growth of the parasite inside, and enhances parasite sensitivity to chloroquine (Brizuela et al., 2014).

\section{Antitrichomonas Activity}

Trichomoniasis is a protozoan infection of the human and bovine urogenital tracts. Metronidazole, Tinidazole and other nitroimidazoles are the most effective drugs, currently available for treatment. In the early 1980s, Glazer and Chappel (1982) reported the synthesis and the activity of a novel series of pyrido[2,3-b]quinoxaline 5-oxides against Trichomonas foetus. Carta et al. (2004) reported the synthesis and antitrichomonas activity of a series of 6,7-difluoro-3-methylquinoxaline 1,4dioxides (Figure 10A). In particular, several 2-phenylthio derivatives resulted 20 - to 30 -fold more potent than the reference drug Metronidazole activity against T. vaginalis (SS22) in vitro, isolated in Italy from a case of acute vaginal trichomoniasis. For example, sulfoxide derivative (Figure 10B) was reported to be more effective than the reference drug metronidazole against T. vaginalis while one compound (Figure 10C) inhibited the 


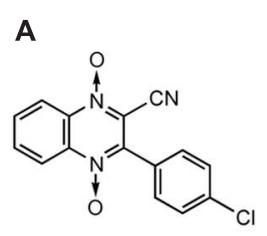<smiles></smiles><smiles>[Y]C(=O)c1c(C(F)(F)F)[n+]([O-])c2cc([R6])c([R6])cc2[n+]1[O-]</smiles><smiles></smiles><smiles>[R6]c1cc2c(cc1[R6])[n+]([O-])c(NS([Y])(=O)=O)c(C)[n+]2[O-]</smiles><smiles>F</smiles>
$\mathbf{F}$

G<smiles>COc1cc(/C=C/C(=O)c2c(C)[n+](O)c3ccccc3[n+]2O)cc(OC)c1OC</smiles><smiles>O[n+]1c(CBr)c(CBr)[n+](O)c2ccccc21</smiles>

FIGURE 9 | QdNOs with antimalarial activity.

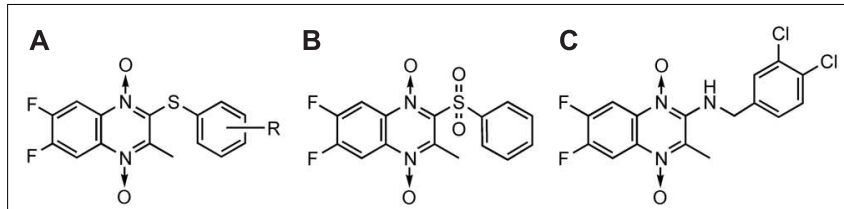

FIGURE 10 | QdNOs with antitrichomonas activity.

growth of T. vaginalis at MIC value of $6.25 \mathrm{mg} / \mathrm{mL}$, after $24 \mathrm{~h}$ of incubation.

\section{Antiamoebic Activity}

Amebiasis is a protozoan infection of human gastrointestinal tract caused by Entamoeba histolytica which results in 500 million cases and approximately 110,000 deaths annually. Out of a new series of ethyl and methyl quinoxaline-7-carboxylate 1,4-di- $N$ oxide derivatives synthesized by Duque-Montano et al. (2013), thiophene bearing motif (Figure 11A; $\mathrm{IC}_{50}=0.35 \mu \mathrm{M}$ ) stood out, having enhanced biological activity which was 11-fold higher than others but having selectivity index $\left[\mathrm{IC}_{50}\right.$ (VERO cells)/IC $\mathrm{I}_{50}$ (E. histolytica)] of 16.74. Compounds T-001 (Figure 11B) and $\mathrm{T}-016$ (Figure 11C) showed $\mathrm{IC}_{50}$ values of 1.41 and $1.47 \mu \mathrm{M}$, respectively, with a value of selectivity index $>60$.

\section{ANTIINFLAMMATORY AND ANTIOXIDANT ACTIVITIES OF QdNOs}

Arachidonic acid metabolism, mediated by the LOX enzyme family, leads to the generation of leukotrienes, a type of pro-inflammatory mediator involved in processes such as fever, asthma, or cardiovascular disease. Additionally, aberrant arachidonic acid metabolism is related to carcinogenesis. For example, increased LOX expression levels have been found in a wide range of cancers, including pancreatic, bladder, and breast cancer (Hofmann and Steinhilber, 2013). During the inflammation process, phagocytic leukocytes produce ROS. A number of commercially available non-steroidal antiinflammatory drugs, such as acetaminophen, salicylates,

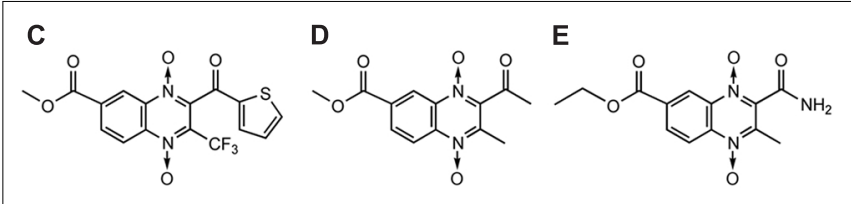

FIGURE 11 | QdNOs with antiamoebic activity.

indomethacin, and nimesulide, have been shown to possess radical scavenging properties. Therefore, the development of new compounds having both antiinflammatory and antioxidant activities and being LOX inhibitors is an interesting approach for cancer prevention, treatment of chronic inflammation and other related pathological conditions.

3-phenyl-1-(1,4-di- $N$-oxide quinoxalin-2-yl)-2-propen-1one derivatives and their 4,5-dihydro- $(1 \mathrm{H})$-pyrazole analogs were discovered to show very interesting antioxidant and antiinflammatory properties. Compound 2a (Figure 12, series 2) displayed an in vivo antiinflammatory effect (56.1\%) higher than the reference drug, indomethacin, and promising in vitro inhibition values of $\operatorname{LOX}\left(\mathrm{IC}_{50}<1 \mu \mathrm{M}\right.$; Burguete et al., 2007). Compound 7b (Figure 12, series 7) showed significant protection against carrageenan-induced paw edema, in which the in vivo antiinflammatory effect $(41 \%)$ was similar to that of indomethacin (47\%; Burguete et al., 2011).

Burguete et al. (2011) has studied the SAR which demonstrates that the radical scavenging ability needs a phenolic group (series 2 ) and/or a free amino pyrazoline ring (series 3, 8, and 10) in the structure (Figure 12). In the presence of the pyrazoline moiety, those with $N$-oxide groups in the quinoxaline ring (series 3 and 10) exhibited significantly increased reducing activity compared to their reduced analogs (series 8), resulting in increased scavenging activity. Compounds with an $\alpha, \beta$-unsaturated ketone system (1b, 2e, 4f, 5a, 5b, 5g, and $6 \mathrm{a}-\mathrm{f}$ ) presented the best $\mathrm{O}_{2}^{\bullet-}$ scavenging activities, indicating that the olefinic moiety might play an important role in the activity by trapping the $\mathrm{O}_{2}^{\bullet-}$. The derivatives are also good ${ }^{\bullet} \mathrm{OH}$ scavengers. In the inhibition of LOX, the best $\mathrm{IC}_{50}$ values were shown by compounds of series 7, 9, and compound 8f. Although compounds that 
<smiles>[R20]c1cc2c(cc1[R20])[n+]([O-])c(C(=O)/C=C/c1cc(OC)c(OC)c(OC)c1)c(C)[n+]2[O-]</smiles>

Series 1

1b, 1e, 1f<smiles>[R6]c1cc2c(cc1[R6])[n+]([O-])c(/C=C/C(=O)c1cc(OC)c(OC)c(OC)c1)c(C)[n+]2[O-]</smiles>

Series 4

$4 a, 4 b, 4 c, 4 d, 4 e, 4 f$<smiles>[R6]c1cc2nc(C)c(-c3cc(-c4cc(OC)c(OC)c(OC)c4)nc(N)n3)nc2cc1[R6]</smiles>

Series 7

7a, 7b, 7c, 7d, 7e<smiles>[R6]c1cc2c(cc1[R6])[n+]([O-])c(C(=O)/C=C/c1ccc(O)c(OC)c1)c(C)[n+]2[O-]</smiles>

Series 2

2a, 2e, 2f<smiles>[R6]c1cc2c(cc1[R7])[n+]([O-])c(/C=C/C(=O)c1ccc(OC)cc1)c[n+]2[O-]</smiles>

Series 5

$5 a, 5 b, 5 d, 5 e, 5 g$<smiles>[R6]c1cc2nc(C)c(C3CC(c4cc(OC)c(OC)c(OC)c4)NN3)nc2cc1[R6]</smiles>

Series 8

8c, $8 f$<smiles>[R9]c1cc2c(cc1[R20])[n+]([O-])c(C1=NNC(c3cc([R3])c([R4])c(OC)c3)C1)c(C)[n+]2[O-]</smiles>

Series $3\left(\mathbf{R}_{3}{ }^{\prime}=R_{4}{ }^{\prime}=\mathrm{OCH}_{3}\right) \quad 3 c, 3 e, 3 f$

Series $10\left(\mathbf{R}_{3}{ }^{\prime}=H ; R_{4}{ }^{\prime}=O H\right) \quad 10 a$<smiles>[R6]c1cc2nc(C)c(C(=O)/C=C/c3cc(OC)c(OC)c(OC)c3)nc2cc1[R6]</smiles>

Series 6

$6 a, 6 b, 6 c, 6 d, 6 e, 6 f$<smiles>[R6]c1cc2nc(C)c(C3=NN(c4ccc(S(N)(=O)=O)cc4)C(c4cc(OC)c(OC)c(OC)c4)C3)nc2cc1[R20]</smiles>

Series 9

9a, 9b, 9c, 9d

R6/R7: $\mathrm{H} / \mathrm{H}(\mathbf{a}) ; \mathrm{H} / \mathrm{F}(\mathbf{b}) ; \mathrm{H} / \mathrm{OCH}_{3}$ (c); $\mathrm{H} / \mathrm{Cl}$ (d); $\mathrm{H}^{-C_{3}}(\mathbf{e}) ; \mathrm{CH}_{3} / \mathrm{CH}_{3}(f) ; \mathrm{F} / \mathrm{F}$ (g)

FIGURE 12 | QdNOs with antiinflammatory and antioxidant activities [adapted from Burguete et al. (2011)].

displayed good activities of inhibition of lipid peroxidation also presented good values of inhibition of LOX, the best inhibitors of lipid peroxidation were those compounds without any substitution in the quinoxaline ring while the best inhibitors of LOX were obtained by fluoro- and methyl-substituted derivatives.

\section{TOXICOLOGICAL EFFECTS OF QdNOs}

The toxicology effects, including short- and long-term toxicities (Fang et al., 2006; Ihsan et al., 2010, 2011; Wang et al., 2010, 2011a,b, 2012), genotoxicity (Ihsan et al., 2013a,b), and photoallergic toxicity (He et al., 2006), have been extensively studied in the veterinary-used QdNOs. The liver is the main target organ of QdNOs, and OLA and MEQ show obvious toxic effect on the kidney and the adrenal gland. High dose of OLA, MEQ, CBX, and QCT can significantly inhibit the growth and development, reproductive function and embryonic development of rats, whereas CYA has minor effect. OLA, CBX, and MEQ have genotoxicity, and CBX shows obvious carcinogenic effects. QCT has certain genetic toxicity, and no genotoxicity has been detected in CYA.

Quinoxaline 1, 4-di- $N$-oxides show mutagenic and DNAdamaging effects on various organisms. Voogd et al. (1980) reported that QDX, CAX, and OLA were mutagenic on Saccharomyces cerevisiae, Klebsiella pneumoniae, S. typhimurium and E. coli, causing base-pair substitutions and frame-shift mutations. Beutin et al. (1981) found that mutagenicity of QdNOs was dependent on the presence of $N$-oxide groups, since 
quinoxaline, a completely reduced derivative of QDX, was not mutagenic, whereas the partially reduced quinoxaline- $N$-oxide exhibited a lower mutagenic activity than QDX. It was suggested that the mutagenicity of QdNOs resulted from the error-prone repair involved in SOS responses (Nunoshiba and Nishioka, 1989). Ihsan et al. (2013a,b) compared the genotoxic potential of QdNOs in Ames test, HGPRT gene mutation test in V79 cells, unscheduled DNA synthesis assay in human peripheral lymphocytes, chromosome aberration test, and micronucleus test in mice bone, and found that OLA, CBX, and MEQ were more genotoxic than QCT and CYA. Using alkalic comet assay, pronounced increase of DNA fragmentation were observed in Vero cells treated with CBX, OLA, and QCT (Chen et al., 2009). In contrast, DNA damage was significantly decreased after incubation with S9 mix, suggesting that the intermediate metabolites of these compounds exerted lower genotoxicity than their parent drugs. Jin et al. (2009) also found that QCT caused significant DNA fragment migration in a dose-dependent manner in human hepatoma (HepG2).

The mutagenicity of QdNOs with antiparasitic activity has also been studied. Introduction of electron-withdrawing substituents at C-6 and/or C-7 of the quinoxaline ring enhanced in vitro biological activity against $T$. cruzi. In addition, this led to the obtainment of non-mutagenic derivatives in both the Ames assays that were performed or their mutagenicity disappeared when performing the assay using metabolic activation (Torres et al., 2013). Using Ames test, Gabay et al. (2014) investigated the mutagenicity of an in-house chemical library of eighty five $\mathrm{N}$-oxide containing heterocycles, and they found that in some cases, a relationship was found between the presence of $\mathrm{N}$-oxide and mutagenicity, and in other cases, such as quinoxaline dioxides with antiparasitic activity, mutagenicity was substituent dependent.

Quinoxaline 1,4-di- $\mathrm{N}$-oxides can produce ROS and cause oxidative cell damage. It was found that OLA induced the increased levels of ROS and 8-OHdG in HepG2 cells, inferring that OLA exerts genotoxic effects in HepG2 cells probably through the ROS-induced oxidative DNA damage (Zou et al., 2009). Using $\gamma$-H2AX as a surrogate marker for DNA damage, Liu et al. (2012) found that MEQ treatment induced cellular DNA damage, which paralleled the chemicalinduced elevation of ROS levels, and expression of the antioxidant enzyme catalase partially alleviated these MEQassociated effects. Huang et al. (2010b) found that OLA irritated a persistent and utmost release of ROS while MEQ made a similar but weaker reaction. CYA, however, had a short and unstable release of intracellular ROS. On the other hand, quinoxalinine-2-carboxylie acid, one of the metabolites of OLA and MEQ, did not cause any significant production of ROS and showed relatively lower toxicity than its parents. Zhang et al. (2014) reported that QCT damaged the antioxidant defense abilities of HepG2 cells by reducing the activities of endogenous antioxidant enzymes, lowering glutathione concentration, and elevating malondialdehyde level. One hundred and sixty QCT-responsive genes were found to be associated with cell proliferation, glucose metabolism, oxidative stress, and apoptosis, such as $\mathrm{NAD}(\mathrm{P}) \mathrm{H}$ dehydrogenase.
However, QCT metabolites (1,4-bisdesoxyquinocetone and 3methylquinoxaline-2-carboxylic acid) showed little effects on HepG2 cells. Wang et al. (2015b) demonstrated that the rank orders of the desoxy and bidesoxy rates in rat and pig liver microsomes were QCT $<$ CBX $<$ MEQ $<$ OLA $<$ CYA and QCT $<$ MEQ $<$ CBX < OLA < CYA, respectively. In rats, porcine primary hepatocytes, and HepG2 cells, oxidative stress indices and DNA damage showed inverse relationships with the deoxidation rate, indicating that faster deoxidation of QdNOs results in lower DNA-damage-induced toxicity.

The molecular mechanism of cell cycle arrest and apoptosis induced by QdNOs were explored. Liu et al. (2012) report that MEQ inhibited cell proliferation by arresting cells at the G2/M phase of the cell cycle. Zou et al. (2011) demonstrated that OLA induced cell cycle arrest to the $\mathrm{S}$ phase and dose-dependent apoptotic cell death in HepG2 cells through a caspase-9 and 3 dependent mitochondrial pathway. Zhang et al. (2013) found that QCT induced apoptosis in HepG2 cells via activation of caspase, interaction of TNF- $\alpha$ and TNFR1 and modulation of the protein levels of Bid, Bax, and Bcl-2, involving the participation of $\mathrm{p} 53, \mathrm{p} 38$, and JNK. c-MYC-dependent activation of the mitochondrial apoptotic pathway may be associated with QCTinduced toxicity (Zhang et al., 2014). Dysregulated or excessive autophagy may lead to 'type II programmed cell death,' which is closely associated with apoptosis. Zhao et al. (2015) showed that OLA-induced autophagy in HepG2 cells is upregulated by Beclin 1 but downregulated by ROS-dependent c-Jun N-terminal protein kinase (JNK).

The organ toxicities of QdNOs have also been studied. Huang et al. (2009) reported the dose-dependent long-term toxicity of MEQ on adrenal gland in male rats, and its mechanism may involve in oxidative stress and steroid hormone biosynthesis pathway. Then, they found the complex interactions of MEQ metabolism, renin-angiotensin-aldosterone system, NADPH oxidase and oxidative stress in response to MEQ-induced tissue toxicity and aldosterone secretion (Huang et al., 2010a). Wang et al. (2015a) estimated the adrenal cell damage induced by QCT and its bidesoxy-QCT (B-QCT) metabolite, and suggested that its toxic effects resulted from $\mathrm{N}$-oxide groups, and its toxic mechanism might involve the interference of the steroid hormone biosynthesis pathway. They also found ROS, the Janus kinase-signal transducer and activator of transcription (JAK/STAT) pathway, suppressors of cytokine signaling and inflammatory cytokines (TNF- $\alpha$ and IL-6) were involved in the liver and spleen toxicities of MEQ (Wang et al., 2011c). Ihsan et al. (2011) verified that MEQ exerted testicular toxicity by causing oxidative stress and steroidal gene expression profiles.

\section{PERSPECTIVES}

The versatile activities of QdNOs are close related to their chemical structures. The two $\mathrm{N}$-oxide groups in the quinoxaline ring are necessary for the antibacterial (Montoya et al., 1998; Ortega et al., 1999; Sainz et al., 1999; Zhang, 2012), antitumor (Solano et al., 2007), anti-Trypanosoma (Aguirre et al., 2004), 
and antimalaria (Zarranz et al., 2005) properties of QdNOs. Some reduced forms of QdNOs, in which the two $\mathrm{N}$-oxide groups are absent, still possess biological activities. We assume the large side chains of these reduced quinoxaline compounds contribute more to the activities, based on the fact that in the 2-quinoxalinecarbonitrile 1,4-dioxides, the replacement of (N,Ndialkyl amino) alkyl amino chain with aromatic rigid moieties (anilines and arylpiperazines) in three position held the potency but reduced the hypoxia-selectivity (Ortega et al., 2000). The different side chains probably affect the desoxy and bidesoxy rates of QdNOs (Wang et al., 2015b), which may result in different levels of activities and toxicities.

For QdNO antitumoral compounds, when the electronwithdrawing nature of the 6(7)-substituent increases, the compound is more readily reduced and show the best activity (Monge et al., 1995b; Solano et al., 2007). This also is the case for antimycobacterial (Jaso et al., 2005), antitrypanosomal (Aguirre et al., 2004; Benitez et al., 2011), and antimalarial (Zarranz et al., 2005) activities. Interestingly, among 2-alkylcarbonyl-3- trifluoromethylquinoxaline 1,4di- $N$-oxide derivatives, anticancer activity depends on the substituents in the carbonyl group, improving in the order: ethyl $<$ isopropyl $<$ tert-butyl $<$ phenyl-ones (Zarranz et al., 2004), while among 6(7)- substituted quinoxaline-2-carboxylate 1,4-dioxide derivatives, anti-TB activity depends on the substituents in the carboxylate group, improving in the following order: tert-butyl < allyl < 2-methoxyethyl < ethyl < benzyl (Jaso et al., 2005). We speculate that the activity of alkyl group substitution must be mainly affected by the substituted carbonyl or carboxylate group, but the large benzene ring itself may contribute more to the anticancer or anti-TB activities.

In summary, SAR studies for QdNOs suggest that the position $\mathrm{C}(2)$ of quinoxaline should be substituted by electronwithdrawing moieties, preferably by a nitrile or an aroyl, an ester, an $N$-substituted amide group or a short brominated alkyl chain (Jampilek, 2014). The position C(3) is most often substituted by short alkyl chain (e.g., $\mathrm{CH} 3, \mathrm{CF} 3$ ) or phenyl. Substitution of $\mathrm{C}(6)$ or $\mathrm{C}(7)$ of $\mathrm{QdNO}$ by $\mathrm{Cl}, \mathrm{F}, \mathrm{CF}_{3}$, or $\mathrm{OCH}_{3}$ is also advantageous. When the nitrile moiety is $\mathrm{C}(2)$ substituent, substituents in other positions should not be so much electron-withdrawing. It can be concluded that generally lipophilic and mostly electronwithdrawing substituents are preferred.

Although it has been generally accepted that QdNOs are prodrugs, transport forms of agents that are reduced to active

\section{REFERENCES}

Aguirre, G., Cerecetto, H., Di Maio, R., Gonzalez, M., Alfaro, M. E., Jaso, A., et al. (2004). Quinoxaline $\mathrm{N}, \mathrm{N}^{\prime}$-dioxide derivatives and related compounds as growth inhibitors of Trypanosoma cruzi. Structure-activity relationships. Bioorg. Med. Chem. Lett. 14, 3835-3839. doi: 10.1016/j.bmcl.2004. 04.088

Alousi, A. M., Boinpally, R., Wiegand, R., Parchment, R., Gadgeel, S., Heilbrun, L. K., et al. (2007). A phase 1 trial of XK469: toxicity profile of a selective topoisomerase IIbeta inhibitor. Invest. New Drugs 25, 147-154. doi: 10.1007/s10637-006-9024-5 metabolites in the body, the modes of actions of QdNOs are still indistinct. The research of the mechanism of actions of QdNOs is in progress, pushing the development of new compounds with more efficient potentials and less harmful effects. Though modes of antitumoral and antibacterial actions of QdNOs are comparatively clear, there are still some puzzles need to be explained. First, the enzyme(s), reducing and activating QdNOs to produce the free radicals, need to be identified. Since free radicals are short-lived, the location of enzyme(s) might indicate the subcellular or molecular target(s) of the drugs. Second, the type of free radical(s) and how they attack DNA or other target(s) should be identified and elucidated. Third, the network of the drug action and the interactions between drugs and organisms should be fully studied. Fortunately, the genomic and proteomic techniques have become effective ways to investigate drug action pathway and discover new drug targets. Furthermore, the research of the mode of action of QdNOs will provide clues to the study of drug resistant and toxicological mechanism, and guide more effective medication of QdNO drugs, e.g., drug combination therapy. For those modes of actions of QdNOs which are still vague, such as antiprotozoal and anticandida activity, researchers are suggested to investigate them according to the already known mechanisms and the SAR of QdNOs combined with new research tools, such as omics technology and 3D-QSAR. A deeper knowledge of the molecular targets of QdNOs is required for the development of new and more specific drugs through a rational design strategy to avoid undesirable side effects.

\section{AUTHOR CONTRIBUTIONS}

GC contributed to the design of the review and wrote the review. WS, CC, LG, HH, and $\mathrm{ZL}$ revised the review. XW and $\mathrm{ZY}$ contributed to the conception of the review.

\section{ACKNOWLEDGMENTS}

This work was supported by the National Natural Science Foundation of China (31502115 and 31272614), and the National Program for Risk Assessment of Quality and Safety of Livestock and Poultry Products (GJFP2016008).

Ancizu, S., Moreno, E., Torres, E., Burguete, A., Perez-Silanes, S., Benitez, D., et al. (2009). Heterocyclic-2-carboxylic acid (3-cyano-1,4-di$\mathrm{N}$-oxidequinoxalin-2-yl)amide derivatives as hits for the development of neglected disease drugs. Molecules 14, 2256-2272. doi: 10.3390/molecules140 62256

Anderson, R. F., Harris, T. A., Hay, M. P., and Denny, W. A. (2003a). Enhanced conversion of DNA radical damage to double strand breaks by 1,2,4benzotriazine 1,4-dioxides linked to a DNA binder compared to tirapazamine. Chem. Res. Toxicol. 16, 1477-1483. doi: 10.1021/tx034116v

Anderson, R. F., Shinde, S. S., Hay, M. P., Gamage, S. A., and Denny, W. A. (2003b). Activation of 3-amino-1,2,4-benzotriazine 1,4-dioxide antitumor agents to 
oxidizing species following their one-electron reduction. J. Am. Chem. Soc. 125, 748-756. doi: 10.1021/ja0209363

Anderson, R. F., Shinde, S. S., Hay, M. P., and Denny, W. A. (2006). Potentiation of the cytotoxicity of the anticancer agent tirapazamine by benzotriazine N-oxides: the role of redox equilibria. J. Am. Chem. Soc. 128, 245-249. doi: $10.1021 / \mathrm{ja} 0559101$

Anderson, R. F., Shinde, S. S., Hay, M. P., Gamage, S. A., and Denny, W. A. (2005). Radical properties governing the hypoxia-selective cytotoxicity of antitumor 3amino-1,2,4-benzotriazine 1,4-dioxides. Org. Biomol. Chem. 3, 2167-2174. doi: $10.1039 / \mathrm{b} 502586 \mathrm{a}$

Anderson, R. F., Yadav, P., Patel, D., Reynisson, J., Tipparaju, S. R., Guise, C. P., et al. (2014). Characterisation of radicals formed by the triazine 1,4-dioxide hypoxia-activated prodrug, SN30000. Org. Biomol. Chem. 12, 3386-3392. doi: $10.1039 /$ c4ob00236a

Baker, J. H., Kyle, A. H., Bartels, K. L., Methot, S. P., Flanagan, E. J., Balbirnie, A., et al. (2013). Targeting the tumour vasculature: exploitation of low oxygenation and sensitivity to NOS inhibition by treatment with a hypoxic cytotoxin. PLoS ONE 8:e76832. doi: 10.1371/journal.pone.0076832

Barea, C., Pabon, A., Castillo, D., Zimic, M., Quiliano, M., Galiano, S., et al. (2011). New salicylamide and sulfonamide derivatives of quinoxaline 1,4-di-N-oxide with antileishmanial and antimalarial activities. Bioorg. Med. Chem. Lett. 21, 4498-4502. doi: 10.1016/j.bmcl.2011.05.125

Barea, C., Pabon, A., Galiano, S., Perez-Silanes, S., Gonzalez, G., Deyssard, C., et al. (2012). Antiplasmodial and leishmanicidal activities of 2-cyano3-(4-phenylpiperazine-1-carboxamido) quinoxaline 1,4-dioxide derivatives. Molecules 17, 9451-9461. doi: 10.3390/molecules 17089451

Barea, C., Pabon, A., Perez-Silanes, S., Galiano, S., Gonzalez, G., Monge, A., et al. (2013). New amide derivatives of quinoxaline 1,4-di-N-oxide with leishmanicidal and antiplasmodial activities. Molecules 18, 4718-4727. doi: 10.3390/molecules 18044718

Bekaii-Saab, T. S., Mortazavi, A., Hicks, L. G., Zalupski, M., Pelley, R. J., Chan, K. K., et al. (2006). A phase II study of chloroquinoxaline sulfonamide (CQS) in patients with metastatic colorectal carcinoma (MCRC). Invest. New Drugs 24, 343-346. doi: 10.1007/s10637-005-4827-3

Benitez, D., Cabrera, M., Hernandez, P., Boiani, L., Lavaggi, M. L., Di Maio, R., et al. (2011). 3-Trifluoromethylquinoxaline N,N'-dioxides as anti-trypanosomatid agents. Identification of optimal anti-T. cruzi agents and mechanism of action studies. J. Med. Chem. 54, 3624-3636. doi: 10.1021/jm2002469

Beutin, L., Preller, E., and Kowalski, B. (1981). Mutagenicity of quindoxin, its metabolites, and two substituted quinoxaline-di-N-oxides. Antimicrob. Agents Chemother. 20, 336-343. doi: 10.1128/AAC.20.3.336

Birincioglu, M., Jaruga, P., Chowdhury, G., Rodriguez, H., Dizdaroglu, M., and Gates, K. S. (2003). DNA base damage by the antitumor agent 3-amino-1,2,4benzotriazine 1,4-dioxide (tirapazamine). J. Am. Chem. Soc. 125, 11607-11615. doi: $10.1021 /$ ja0352146

Brizuela, M., Huang, H. M., Smith, C., Burgio, G., Foote, S. J., and McMorran, B. J. (2014). Treatment of erythrocytes with the 2-cys peroxiredoxin inhibitor, Conoidin A, prevents the growth of Plasmodium falciparum and enhances parasite sensitivity to chloroquine. PLOS ONE 9:e92411. doi: 10.1371/journal.pone.0092411

Brown, J. M. (1999). The hypoxic cell: a target for selective cancer therapyeighteenth Bruce F. Cain Memorial Award lecture. Cancer Res. 59, 5863-5870.

Burguete, A., Pontiki, E., Hadjipavlou-Litina, D., Ancizu, S., Villar, R., Solano, B., et al. (2011). Synthesis and biological evaluation of new quinoxaline derivatives as antioxidant and anti-inflammatory agents. Chem. Biol. Drug Des. 77, 255267. doi: 10.1111/j.1747-0285.2011.01076.x

Burguete, A., Pontiki, E., Hadjipavlou-Litina, D., Villar, R., Vicente, E., Solano, B., et al. (2007). Synthesis and anti-inflammatory/antioxidant activities of some new ring substituted 3-phenyl-1-(1,4-di-N-oxide quinoxalin-2-yl)-2-propen-1one derivatives and of their 4,5-dihydro- $(1 \mathrm{H})$-pyrazole analogues. Bioorg. Med. Chem. Lett. 17, 6439-6443. doi: 10.1016/j.bmcl.2007.10.002

Cai, T. Y., Liu, X. W., Zhu, H., Cao, J., Zhang, J., Ding, L., et al. (2014). Tirapazamine sensitizes hepatocellular carcinoma cells to topoisomerase I inhibitors via cooperative modulation of hypoxia-inducible factor-1alpha. Mol. Cancer Ther. 13, 630-642. doi: 10.1158/1535-7163.MCT-13-0490

Carey, K. L., Westwood, N. J., Mitchison, T. J., and Ward, G. E. (2004). A smallmolecule approach to studying invasive mechanisms of Toxoplasma gondii. Proc. Natl. Acad. Sci. U.S.A. 101, 7433-7438. doi: 10.1073/pnas.0307769101
Carmeliet, P., Dor, Y., Herbert, J. M., Fukumura, D., Brusselmans, K., Dewerchin, M., et al. (1998). Role of HIF-1alpha in hypoxia-mediated apoptosis, cell proliferation and tumour angiogenesis. Nature 394, 485-490. doi: $10.1038 / 28867$

Carta, A., Corona, P., and Loriga, M. (2005). Quinoxaline 1,4-dioxide: a versatile scaffold endowed with manifold activities. Curr. Med. Chem. 12, 2259-2272. doi: 10.2174/0929867054864831

Carta, A., Loriga, M., Paglietti, G., Mattana, A., Fiori, P. L., Mollicotti, P., et al. (2004). Synthesis, anti-mycobacterial, anti-trichomonas and anticandida in vitro activities of 2-substituted-6,7-difluoro-3-methylquinoxaline 1,4-dioxides. Eur. J. Med. Chem. 39, 195-203. doi: 10.1016/j.ejmech.2003.11.008

Carta, A., Paglietti, G., Rahbar Nikookar, M. E., Sanna, P., Sechi, L., and Zanetti, S. (2002). Novel substituted quinoxaline 1,4-dioxides with in vitro antimycobacterial and anticandida activity. Eur. J. Med. Chem. 37, 355-366. doi: 10.1016/S0223-5234(02)01346-6

Cerecetto, H., Di Maio, R., Gonzalez, M., Risso, M., Saenz, P., Seoane, G., et al. (1999). 1,2,5-Oxadiazole N-oxide derivatives and related compounds as potential antitrypanosomal drugs: structure-activity relationships. J. Med. Chem. 42, 1941-1950. doi: 10.1021/jm9805790

Chen, Q., Tang, S., Jin, X., Zou, J., Chen, K., Zhang, T., et al. (2009). Investigation of the genotoxicity of quinocetone, carbadox and olaquindox in vitro using Vero cells. Food Chem. Toxicol. 47, 328-334. doi: 10.1016/j.fct.2008.11.020

Cheng, G., Li, B., Wang, C., Zhang, H., Liang, G., Weng, Z., et al. (2015). Systematic and molecular basis of the antibacterial action of quinoxaline 1,4-Di-N-oxides against Escherichia coli. PLoS ONE 10:e0136450. doi: 10.1371/journal.pone.0136450

Chinje, E. C., Cowen, R. L., Feng, J., Sharma, S. P., Wind, N. S., Harris, A. L., et al. (2003). Non-nuclear localized human NOSII enhances the bioactivation and toxicity of tirapazamine (SR4233) in vitro. Mol. Pharmacol. 63, 1248-1255. doi: 10.1124/mol.63.6.1248

Chowdhury, G., Junnotula, V., Daniels, J. S., Greenberg, M. M., and Gates, K. S. (2007). DNA strand damage product analysis provides evidence that the tumor cell-specific cytotoxin tirapazamine produces hydroxyl radical and acts as a surrogate for $\mathrm{O}(2)$. J. Am. Chem. Soc. 129, 12870-12877. doi: $10.1021 / \mathrm{ja0} 07432 \mathrm{~m}$

Cihak, R., and Srb, V. (1983). Cytogenetic effects of quinoxaline-1,4-dioxidetype growth-promoting agents. I. Micronucleus test in rats. Mutat. Res. 116, 129-135.

Cohen, E. E., Rosine, D., Haraf, D. J., Loh, E., Shen, L., Lusinchi, A., et al. (2007). Phase I trial of tirapazamine, cisplatin, and concurrent accelerated boost reirradiation in patients with recurrent head and neck cancer. Int. J. Radiat. Oncol. Biol. Phys. 67, 678-684. doi: 10.1016/j.ijrobp.2006.09.056

Covens, A., Blessing, J., Bender, D., Mannel, R., and Morgan, M. (2006). A phase II evaluation of tirapazamine plus cisplatin in the treatment of recurrent platinum-sensitive ovarian or primary peritoneal cancer: a Gynecologic Oncology Group study. Gynecol. Oncol. 100, 586-590. doi: 10.1016/j.ygyno.2005.09.032

Das, N. K. (1984). In vitro susceptibility of Escherichia coli of swine origin to carbadox and other antimicrobials. Am. J. Vet. Res. 45, 252-254.

Das, U., Pati, H. N., Panda, A. K., De Clercq, E., Balzarini, J., Molnar, J., et al. (2009). 2-(3-Aryl-2-propenoyl)-3-methylquinoxaline-1,4-dioxides: a novel cluster of tumor-specific cytotoxins which reverse multidrug resistance. Bioorg. Med. Chem. 17, 3909-3915. doi: 10.1016/j.bmc.2009.04.021

Delahoussaye, Y. M., Evans, J. W., and Brown, J. M. (2001). Metabolism of tirapazamine by multiple reductases in the nucleus. Biochem. Pharmacol. 62, 1201-1209. doi: 10.1016/S0006-2952(01)00784-5

Diab-Assef, M., Haddadin, M. J., Yared, P., Assaad, C., and Gali-Muhtasib, H. U. (2002). Quinoxaline 1,4-dioxides: hypoxia-selective therapeutic agents. Mol. Carcinog. 33, 198-205. doi: 10.1002/mc.10036

Ding, M. X., Wang, Y. L., Zhu, H. L., and Yuan, Z. H. (2006a). Effects of cyadox and olaquindox on intestinal mucosal immunity and on fecal shedding of Escherichia coli in piglets. J. Anim. Sci. 84, 2367-2373. doi: 10.2527/jas.2005-564

Ding, M. X., Yuan, Z. H., Wang, Y. L., Zhu, H. L., and Fan, S. X. (2006b). Olaquindox and cyadox stimulate growth and decrease intestinal mucosal immunity of piglets orally inoculated with Escherichia coli. J. Anim. Physiol. Anim. Nutr. 90, 238-243. doi: 10.1111/j.1439-0396.2005.00593.x

Downing, J. C. (1974). Carbadox for control of swine dysentery. Mod. Vet. Pract. $55,167-168$ passim. 
Drumev, D. (1981). [Current animal feeds with antimicrobial activity]. Vet. Med. Nauki 18, 10-25.

Duque-Montano, B. E., Gomez-Caro, L. C., Sanchez-Sanchez, M., Monge, A., Hernandez-Baltazar, E., Rivera, G., et al. (2013). Synthesis and in vitro evaluation of new ethyl and methyl quinoxaline-7-carboxylate 1,4-di-Noxide against Entamoeba histolytica. Bioorg. Med. Chem. 21, 4550-4558. doi: 10.1016/j.bmc.2013.05.036

Estevez, Y., Quiliano, M., Burguete, A., Cabanillas, B., Zimic, M., Malaga, E., et al. (2011). Trypanocidal properties, structure-activity relationship and computational studies of quinoxaline 1,4-di-N-oxide derivatives. Exp. Parasitol. 127, 745-751. doi: 10.1016/j.exppara.2011.01.009

European Union [EU] (1998). Commission Regulation (EC) No. 2788/98. Off. J. Eur. Commun. L347:3.

Evans, J. W., Chernikova, S. B., Kachnic, L. A., Banath, J. P., Sordet, O., Delahoussaye, Y. M., et al. (2008). Homologous recombination is the principal pathway for the repair of DNA damage induced by tirapazamine in mammalian cells. Cancer Res. 68, 257-265. doi: 10.1158/0008-5472. CAN-06-4497

Evans, J. W., Yudoh, K., Delahoussaye, Y. M., and Brown, J. M. (1998). Tirapazamine is metabolized to its DNA-damaging radical by intranuclear enzymes. Cancer Res. 58, 2098-2101.

Fang, G., He, Q., Zhou, S., Wang, D., Zhang, Y., and Yuan, Z. (2006). Subchronic oral toxicity study with cyadox in Wistar rats. Food Chem. Toxicol. 44, 36-41. doi: 10.1016/j.fct.2005.06.003

Gabay, M., Cabrera, M., Maio, R. D., Paez, J. A., Campillo, N., Lavaggi, M. L., et al. (2014). Mutagenicity of N-oxide containing heterocycles and related compounds: experimental and theoretical studies. Curr. Top. Med. Chem. 14, 1374-1387. doi: 10.2174/1568026614666140506123235

Ganley, B., Chowdhury, G., Bhansali, J., Daniels, J. S., and Gates, K. S. (2001). Redox-activated, hypoxia-selective DNA cleavage by quinoxaline 1,4di-N-oxide. Bioorg. Med. Chem. 9, 2395-2401. doi: 10.1016/S0968-0896(01) 00163-8

Gao, H., Huang, K. C., Yamasaki, E. F., Chan, K. K., Chohan, L., and Snapka, R. M. (1999). XK469, a selective topoisomerase IIbeta poison. Proc. Natl. Acad. Sci. U.S.A. 96, 12168-12173. doi: 10.1073/pnas.96.21.12168

Gao, H., Yamasaki, E. F., Chan, K. K., Shen, L. L., and Snapka, R. M. (2000). Chloroquinoxaline sulfonamide (NSC 339004) is a topoisomerase IIalpha/beta poison. Cancer Res. 60, 5937-5940.

Gerpe, A., Boiani, L., Hernandez, P., Sortino, M., Zacchino, S., Gonzalez, M., et al. (2010). Naftifine-analogues as anti-Trypanosoma cruzi agents. Eur. J. Med. Chem. 45, 2154-2164. doi: 10.1016/j.ejmech.2010.01.052

Ghattass, K., El-Sitt, S., Zibara, K., Rayes, S., Haddadin, M. J., El-Sabban, M., et al. (2014). The quinoxaline di-N-oxide DCQ blocks breast cancer metastasis in vitro and in vivo by targeting the hypoxia inducible factor-1 pathway. Mol. Cancer 13, 12. doi: 10.1186/1476-4598-13-12

Gil, A., Pabon, A., Galiano, S., Burguete, A., Perez-Silanes, S., Deharo, E., et al. (2014). Synthesis, biological evaluation and structure-activity relationships of new quinoxaline derivatives as anti-Plasmodium falciparum agents. Molecules 19, 2166-2180. doi: 10.3390/molecules 19022166

Glazer, E. A., and Chappel, L. R. (1982). Pyridoquinoxaline N-oxides. 1. A new class of antitrichomonal agents. J. Med. Chem. 25, 766-769. doi: 10.1021/jm00349a021

Guo, W., Hao, H., Dai, M., Wang, Y., Huang, L., Peng, D., et al. (2012). Development of quinoxaline 1,4-dioxides resistance in Escherichia coli and molecular change under resistance selection. PLOS ONE 7:e43322. doi: 10.1371/journal.pone.0043322

Hansen, L. H., Jensen, L. B., Sorensen, H. I., and Sorensen, S. J. (2007). Substrate specificity of the OqxAB multidrug resistance pump in Escherichia coli and selected enteric bacteria. J. Antimicrob. Chemother. 60, 145-147. doi: 10.1093/jac/dkm167

Hansen, L. H., Johannesen, E., Burmolle, M., Sorensen, A. H., and Sorensen, S. J. (2004). Plasmid-encoded multidrug efflux pump conferring resistance to olaquindox in Escherichia coli. Antimicrob. Agents Chemother. 48, 3332-3337. doi: 10.1128/AAC.48.9.3332-3337.2004

Hansen, L. H., Sorensen, S. J., Jorgensen, H. S., and Jensen, L. B. (2005). The prevalence of the OqxAB multidrug efflux pump amongst olaquindoxresistant Escherichia coli in pigs. Microbiol. Drug Resist. 11, 378-382. doi: 10.1089/mdr.2005.11.378
Haraldsen, J. D., Liu, G., Botting, C. H., Walton, J. G., Storm, J., Phalen, T. J., et al. (2009). Identification of conoidin a as a covalent inhibitor of peroxiredoxin II. Org. Biomol. Chem. 7, 3040-3048. doi: 10.1039/b901735f

He, Q., Fang, G., Wang, Y., Wei, Z., Wang, D., Zhou, S., et al. (2006). Experimental evaluation of cyadox phototoxicity to Balb/c mouse skin. Photodermatol. Photoimmunol. Photomed. 22, 100-104. doi: 10.1111/j.1600-0781.2006.00199.x

Hellauer, K., Lesage, G., Sdicu, A. M., and Turcotte, B. (2005). Largescale analysis of genes that alter sensitivity to the anticancer drug tirapazamine in Saccharomyces cerevisiae. Mol. Pharmacol. 68, 1365-1375. doi: 10.1124/mol.105.012963

Hicks, K. O., Siim, B. G., Jaiswal, J. K., Pruijn, F. B., Fraser, A. M., Patel, R., et al. (2010). Pharmacokinetic/pharmacodynamic modeling identifies SN30000 and SN29751 as tirapazamine analogues with improved tissue penetration and hypoxic cell killing in tumors. Clin. Cancer Res. 16, 4946-4957. doi: 10.1158/1078-0432.CCR-10-1439

Hofmann, B., and Steinhilber, D. (2013). 5-Lipoxygenase inhibitors: a review of recent patents (2010-2012). Expert Opin. Ther. Pat. 23, 895-909. doi: $10.1517 / 13543776.2013 .791678$

Huang, X. J., Ihsan, A., Wang, X., Dai, M. H., Wang, Y. L., Su, S. J., et al. (2009). Long-term dose-dependent response of Mequindox on aldosterone, corticosterone and five steroidogenic enzyme mRNAs in the adrenal of male rats. Toxicol. Lett. 191, 167-173. doi: 10.1016/j.toxlet.2009.08.021

Huang, X. J., Wang, X., Ihsan, A., Liu, Q., Xue, X. J., Su, S. J., et al. (2010a). Interactions of NADPH oxidase, renin-angiotensin-aldosterone system and reactive oxygen species in mequindox-mediated aldosterone secretion in Wistar rats. Toxicol. Lett. 198, 112-118. doi: 10.1016/j.toxlet.2010.05.013

Huang, X. J., Zhang, H. H., Wang, X., Huang, L. L., Zhang, L. Y., Yan, C. X., et al. (2010b). ROS mediated cytotoxicity of porcine adrenocortical cells induced by QdNOs derivatives in vitro. Chem. Biol. Interact. 185, 227-234. doi: 10.1016/j.cbi.2010.02.030

Hunter, F. W., Hsu, H. L., Su, J., Pullen, S. M., Wilson, W. R., and Wang, J. (2014a). Dual targeting of hypoxia and homologous recombination repair dysfunction in triple-negative breast cancer. Mol. Cancer Ther. 13, 2501-2514. doi: 10.1158/1535-7163.MCT-14-0476

Hunter, F. W., Jaiswal, J. K., Hurley, D. G., Liyanage, H. D., McManaway, S. P., $\mathrm{Gu}$, Y., et al. (2014b). The flavoprotein FOXRED2 reductively activates nitrochloromethylbenzindolines and other hypoxia-targeting prodrugs. Biochem. Pharmacol. 89, 224-235. doi: 10.1016/j.bcp.2014.03.001

Hunter, F. W., Young, R. J., Shalev, Z., Vellanki, R. N., Wang, J., Gu, Y., et al. (2015). Identification of $\mathrm{P} 450$ oxidoreductase as a major determinant of sensitivity to hypoxia-activated prodrugs. Cancer Res. 75, 4211-4223. doi: 10.1158/00085472.CAN-15-1107

Ihsan, A., Wang, X., Huang, X. J., Liu, Y., Liu, Q., Zhou, W., et al. (2010). Acute and subchronic toxicological evaluation of Mequindox in Wistar rats. Regul. Toxicol. Pharmacol. 57, 307-314. doi: 10.1016/j.yrtph.2010.03.011

Ihsan, A., Wang, X., Liu, Z., Wang, Y., Huang, X., Liu, Y., et al. (2011). Longterm mequindox treatment induced endocrine and reproductive toxicity via oxidative stress in male Wistar rats. Toxicol. Appl. Pharmacol. 252, 281-288. doi: 10.1016/j.taap.2011.02.020

Ihsan, A., Wang, X., Tu, H. G., Zhang, W., Dai, M. H., Peng, D. P., et al. (2013a). Genotoxicity evaluation of Mequindox in different short-term tests. Food Chem. Toxicol. 51, 330-336. doi: 10.1016/j.fct.2012.10.003

Ihsan, A., Wang, X., Zhang, W., Tu, H., Wang, Y., Huang, L., et al. (2013b). Genotoxicity of quinocetone, cyadox and olaquindox in vitro and in vivo. Food Chem. Toxicol. 59, 207-214. doi: 10.1016/j.fct.2013.06.008

Ismail, M. M., Amin, K. M., Noaman, E., Soliman, D. H., and Ammar, Y. A. (2010). New quinoxaline 1, 4-di-N-oxides: anticancer and hypoxia-selective therapeutic agents. Eur. J. Med. Chem. 45, 2733-2738. doi: 10.1016/j.ejmech.2010.02.052

Jampilek, J. (2014). Recent advances in design of potential quinoxaline anti-infectives. Curr. Med. Chem. 21, 4347-4373. doi: $10.2174 / 0929867321666141011194825$

Jaso, A., Zarranz, B., Aldana, I., and Monge, A. (2003). Synthesis of new 2-acetyl and 2-benzoyl quinoxaline 1,4-di-N-oxide derivatives as anti-Mycobacterium tuberculosis agents. Eur. J. Med. Chem. 38, 791-800. doi: 10.1016/S02235234(03)00137-5

Jaso, A., Zarranz, B., Aldana, I., and Monge, A. (2005). Synthesis of new quinoxaline-2-carboxylate 1,4-dioxide derivatives as anti-Mycobacterium tuberculosis agents. J. Med. Chem. 48, 2019-2025. doi: 10.1021/jm049952w 
Jin, X., Chen, Q., Tang, S. S., Zou, J. J., Chen, K. P., Zhang, T., et al. (2009). Investigation of quinocetone-induced genotoxicity in HepG2 cells using the comet assay, cytokinesis-block micronucleus test and RAPD analysis. Toxicol. In Vitro 23, 1209-1214. doi: 10.1016/j.tiv.2009.07.038

Kotandeniya, D., Ganley, B., and Gates, K. S. (2002). Oxidative DNA base damage by the antitumor agent 3-amino-1,2,4-benzotriazine 1,4-dioxide (tirapazamine). Bioorg. Med. Chem. Lett. 12, 2325-2329. doi: 10.1016/S0960894X(02)00468-7

Laderoute, K. R., and Rauth, A. M. (1986). Identification of two major reduction products of the hypoxic cell toxin 3-amino-1,2,4-benzotriazine1,4-dioxide. Biochem. Pharmacol. 35, 3417-3420. doi: 10.1016/0006-2952(86) 90448-X

Laderoute, K., Wardman, P., and Rauth, A. M. (1988). Molecular mechanisms for the hypoxia-dependent activation of 3-amino-1,2,4-benzotriazine-1,4dioxide (SR 4233). Biochem. Pharmacol. 37, 1487-1495. doi: 10.1016/00062952(88)90010-X

Lawn, S. D., and Zumla, A. I. (2011). Tuberculosis. Lancet 378, 57-72. doi: 10.1016/S0140-6736(10)62173-3

Liu, J., Ouyang, M., Jiang, J., Mu, P., Wu, J., Yang, Q., et al. (2012). Mequindox induced cellular DNA damage via generation of reactive oxygen species. Mutat. Res. 741, 70-75. doi: 10.1016/j.mrgentox.2011.10.012

Lloyd, R. V., Duling, D. R., Rumyantseva, G. V., Mason, R. P., and Bridson, P. K. (1991). Microsomal reduction of 3-amino-1,2,4-benzotriazine 1,4-dioxide to a free radical. Mol. Pharmacol. 40, 440-445.

Maluf, F. C., Leiser, A. L., Aghajanian, C., Sabbatini, P., Pezzulli, S., Chi, D. S., et al. (2006). Phase II study of tirapazamine plus cisplatin in patients with advanced or recurrent cervical cancer. Int. J. Gynecol. Cancer 16, 1165-1171. doi: 10.1111/j.1525-1438.2006.00454.x

Marin, A., Moreira Lima, L., Solano, B., Vicente, E., Perez Silanes, S., Maurel, S., et al. (2008). Antiplasmodial structure-activity relationship of 3-trifluoromethyl-2-arylcarbonylquinoxaline 1,4-di-N-oxide derivatives. Exp. Parasitol. 118, 25-31. doi: 10.1016/j.exppara.2007.05.009

McIlwain, H. J. (1943). Bacterial inhibition by metabolite analogues. Part V. Reactions and antibacterial properties of p-diazine di-n-oxides. J. Chem. Soc. 1943, 322-325. doi: 10.1039/jr9430000322

Miller, V. A., Rigas, J. R., Tong, W. P., Reid, J. R., Pisters, K. M., Grant, S. C., et al. (1997). Phase II trial of chloroquinoxaline sulfonamide (CQS) in patients with stage III and IV non-small-cell lung cancer. Cancer Chemother. Pharmacol. 40, 415-418. doi: $10.1007 / \mathrm{s} 002800050679$

Ministry of Agriculture of P. R. China (2003). Notice No. 295. Beijing: Ministry of Agriculture.

Miyake, K., Nishioka, M., Imura, S., Batmunkh, E., Uto, Y., Nagasawa, H., et al. (2012). The novel hypoxic cytotoxin, TX-2098 has antitumor effect in pancreatic cancer; possible mechanism through inhibiting VEGF and hypoxia inducible factor-1alpha targeted gene expression. Exp. Cell Res. 318, 1554-1563. doi: 10.1016/j.yexcr.2012.03.013

Monge, A., Martinez-Crespo, F. J., Lopez de Cerain, A., Palop, J. A., Narro, S., Senador, V., et al. (1995a). Hypoxia-selective agents derived from 2quinoxalinecarbonitrile 1,4-di-N-oxides. 2. J. Med. Chem. 38, 4488-4494. doi: 10.1021/jm00010a023

Monge, A., Palop, J. A., Lopez de Cerain, A., Senador, V., Martinez-Crespo, F. J., Sainz, Y., et al. (1995b). Hypoxia-selective agents derived from quinoxaline 1,4-di-N-oxides. J. Med. Chem. 38, 1786-1792. doi: 10.1021/jm00010a023

Montoya, M. E., Sainz, Y., Ortega, M. A., Lopez De Cerain, A., and Monge, A. (1998). Synthesis and antituberculosis activity of some new 2-quinoxalinecarbonitriles. Farmaco 53, 570-573. doi: 10.1016/S0014-827X(98)00067-6

Murthy, Y. L. N., Mani, P., Govindh, B., Diwakar, B. S., Karthikeyan, N., Rao, T. R., et al. (2011). Synthesis and characterization of 2,3-diphenyl quinoxaline 1,4-di$\mathrm{N}$-oxide derivatives and study of their antimicrobial activities. Res. J. Pharm. Biol. Chem. Sci. 2, 553-560.

Nagasawa, H., Mikamo, N., Nakajima, Y., Matsumoto, H., Uto, Y., and Hori, H. (2003). Antiangiogenic hypoxic cytotoxin TX-402 inhibits hypoxia-inducible factor 1 signaling pathway. Anticancer Res. 23, 4427-4434.

Nguyen, J. B., Pool, C. D., Wong, C. Y., Treger, R. S., Williams, D. L., Cappello, M., et al. (2013). Peroxiredoxin-1 from the human hookworm Ancylostoma ceylanicum forms a stable oxidized decamer and is covalently inhibited by conoidin A. Chem. Biol. 20, 991-1001. doi: 10.1016/j.chembiol.2013.06.011
Noblia, P., Vieites, M., Torre, M. H., Costa-Filho, A. J., Cerecetto, H., Gonzalez, M., et al. (2006). Novel vanadyl complexes with quinoxaline $\mathrm{N}(1), \mathrm{N}(4)$-dioxide derivatives as potent in vitro insulin-mimetic compounds. J. Inorg. Biochem. 100, 281-287. doi: 10.1016/j.jinorgbio.2005.11.012

Nunoshiba, T., and Nishioka, H. (1989). Genotoxicity of quinoxaline 1,4-dioxide derivatives in Escherichia coli and Salmonella typhimurium. Mutat. Res. 217, 203-209. doi: 10.1016/0921-8777(89)90072-4

Olive, P. L. (1995). Detection of hypoxia by measurement of DNA damage in individual cells from spheroids and murine tumours exposed to bioreductive drugs. II. RSU 1069. Br. J. Cancer 71, 537-542. doi: 10.1038/bjc.1995.106

Ortega, M. A., Montoya, M. E., Jaso, A., Zarranz, B., Tirapu, I., Aldana, I., et al. (2001). Antimycobacterial activity of new quinoxaline-2-carbonitrile and quinoxaline-2-carbonitrile 1,4-di-N-oxide derivatives. Pharmazie 56, 205-207.

Ortega, M. A., Morancho, M. J., Martinez-Crespo, F. J., Sainz, Y., Montoya, M. E., Lopez de Cerain, A., et al. (2000). New quinoxalinecarbonitrile 1,4-di-N-oxide derivatives as hypoxic-cytotoxic agents. Eur. J. Med. Chem. 35, 21-30. doi: 10.1016/S0223-5234(00)00112-4

Ortega, M. A., Sainz, Y., Montoya, M. E., Jaso, A., Zarranz, B., Aldana, I., et al. (2002). Anti-Mycobacterium tuberculosis agents derived from quinoxaline-2-carbonitrile and quinoxaline-2-carbonitrile 1,4-di-N-oxide. Arzneimittelforschung 52, 113-119.

Ortega, M. A., Sainz, Y., Montoya, M. E., Lopez De Cerain, A., and Monge, A. (1999). Synthesis and antituberculosis activity of new 2-quinoxalinecarbonitrile 1,4-di-N-oxides. Pharmazie 54, 24-25.

Patterson, A. V., Barham, H. M., Chinje, E. C., Adams, G. E., Harris, A. L., and Stratford, I. J. (1995). Importance of P450 reductase activity in determining sensitivity of breast tumour cells to the bioreductive drug, tirapazamine (SR 4233). Br. J. Cancer 72, 1144-1150. doi: 10.1038/bjc.1995.478

Patterson, A. V., Robertson, N., Houlbrook, S., Stephens, M. A., Adams, G. E., Harris, A. L., et al. (1994). The role of DT-diaphorase in determining the sensitivity of human tumor cells to tirapazamine (SR 4233). Int. J. Radiat. Oncol. Biol. Phys. 29, 369-372. doi: 10.1016/0360-3016(94)90291-7

Patterson, A. V., Saunders, M. P., Chinje, E. C., Talbot, D. C., Harris, A. L., and Strafford, I. J. (1997). Overexpression of human NADPH:cytochrome c (P450) reductase confers enhanced sensitivity to both tirapazamine (SR 4233) and RSU 1069. Br. J. Cancer 76, 1338-1347. doi: 10.1038/bjc.1997.558

Patterson, L. H., and Taiwo, F. A. (2000). Electron paramagnetic resonance spectrometry evidence for bioreduction of tirapazamine to oxidising free radicals under anaerobic conditions. Biochem. Pharmacol. 60, 1933-1935. doi: 10.1016/S0006-2952(00)00487-1

Peters, K. B., and Brown, J. M. (2002). Tirapazamine: a hypoxia-activated topoisomerase II poison. Cancer Res. 62, 5248-5253.

Peters, K. B., Wang, H., Brown, J. M., and Iliakis, G. (2001). Inhibition of DNA replication by tirapazamine. Cancer Res. 61, 5425-5431.

Pommier, Y., Leo, E., Zhang, H. L., and Marchand, C. (2010). DNA topoisomerases and their poisoning by anticancer and antibacterial drugs. Chem. Biol. 17, 421-433. doi: 10.1016/j.chembiol.2010.04.012

Quinones, J. L., Thapar, U., Yu, K., Fang, Q., Sobol, R. W., and Demple, B. (2015). Enzyme mechanism-based, oxidative DNA-protein cross-links formed with DNA polymerase beta in vivo. Proc. Natl. Acad. Sci. U.S.A. 112, 8602-8607. doi: 10.1073/pnas.1501101112

Radwan, A. A., and Abdel-Mageed, W. M. (2014). In silico studies of quinoxaline-2-carboxamide 1,4-di-n-oxide derivatives as antimycobacterial agents. Molecules 19, 2247-2260. doi: 10.3390/molecules 19022247

Rainier, R. H., Chalquest, R. R., Babcock, W. E., and Thrasher, G. W. (1973a). Efficacy of carbadox in prevention of field outbreaks of swine dysentery. Vet. Med. Small Anim. Clin. 68, 171-175.

Rainier, R. H., Chalquest, R. R., Babcock, W. E., and Thrasher, G. W. (1973b). Evaluation of carbadox for prophylaxis and treatment of induced swine dysentery. J. Am. Vet. Med. Assoc. 163, 457-461.

Refaat, H. M., Moneer, A. A., and Khalil, O. M. (2004). Synthesis and antimicrobial activity of certain novel quinoxalines. Arch. Pharm. Res. 27, 1093-1098. doi: 10.1007/BF02975110

Sainz, Y., Montoya, M. E., Martinez-Crespo, F. J., Ortega, M. A., Lopez de Cerain, A., and Monge, A. (1999). New quinoxaline 1,4-di-N-oxides for treatment of tuberculosis. Arzneimittelforschung 49, 55-59.

Shah, Z., Mahbuba, R., and Turcotte, B. (2013). The anticancer drug tirapazamine has antimicrobial activity against Escherichia coli, Staphylococcus aureus and 
Clostridium difficile. FEMS Microbiol. Lett. 347, 61-69. doi: 10.1111/15746968.12223

Shinde, S. S., Hay, M. P., Patterson, A. V., Denny, W. A., and Anderson, R. F. (2009). Spin trapping of radicals other than the ${ }^{\star} \mathrm{OH}$ radical upon reduction of the anticancer agent tirapazamine by cytochrome $\mathrm{P} 450$ reductase. J. Am. Chem. Soc. 131, 14220-14221. doi: 10.1021/ja906860a

Shinde, S. S., Maroz, A., Hay, M. P., Patterson, A. V., Denny, W. A., and Anderson, R. F. (2010). Characterization of radicals formed following enzymatic reduction of 3-substituted analogues of the hypoxia-selective cytotoxin 3-amino-1,2,4benzotriazine 1,4-dioxide (tirapazamine). J. Am. Chem. Soc. 132, 2591-2599. doi: $10.1021 / \mathrm{ja} 908689 \mathrm{f}$

Siim, B. G., van Zijl, P. L., and Brown, J. M. (1996). Tirapazamine-induced DNA damage measured using the comet assay correlates with cytotoxicity towards hypoxic tumour cells in vitro. Br. J. Cancer 73, 952-960. doi: 10.1038/bjc.1996.187

Singh, D. C. P., Hashim, S. R., and Singhal, R. G. (2011). Synthesis and antimicrobial activity of some new thioether derivatives of quinoxaline. J. Chem. 8, 635-642. doi: 10.1155/2011/482831

Singh, D. P., Deivedi, S. K., Hashim, S. R., and Singhal, R. G. (2010). Synthesis and antimicrobial activity of some new quinoxaline derivatives. Pharmaceuticals 3 , 2416-2425. doi: 10.3390/ph3082416

Solano, B., Junnotula, V., Marin, A., Villar, R., Burguete, A., Vicente, E., et al. (2007). Synthesis and biological evaluation of new 2-arylcarbonyl3-trifluoromethylquinoxaline 1,4-di-N-oxide derivatives and their reduced analogues. J. Med. Chem. 50, 5485-5492. doi: 10.1021/jm0 703993

Standing Committee for Animal Nutrition [SCAN] (ed.) (1998). Short Report of the Meeting of the Standing Committee for Animal Nutrition, SCAN. Brussels: European Commission, Health and Food Safety.

Sung, J. S., and Demple, B. (2006). Analysis of base excision DNA repair of the oxidative lesion 2-deoxyribonolactone and the formation of DNAprotein cross-links. Methods Enzymol. 408, 48-64. doi: 10.1016/S0076-6879(06) 08004-9

Suter, W., Rosselet, A., and Knusel, F. (1978). Mode of action of quindoxin and substituted quinoxaline-di-N-oxides on Escherichia coli. Antimicrob. Agents Chemother. 13, 770-783. doi: 10.1128/AAC.13.5.770

Tarallo, M. B., Urquiola, C., Monge, A., Costa, B. P., Ribeiro, R. R., CostaFilho, A. J., et al. (2010). Design of novel iron compounds as potential therapeutic agents against tuberculosis. J. Inorg. Biochem. 104, 1164-1170. doi: 10.1016/j.jinorgbio.2010.07.005

Tarallo, M. B., Urquiola, C., Monge, A., Pavan, F. R., Leite, C. Q., Torre, M. H., et al. (2008). Novel iron complexes with quinoxaline N-1,N-4-dioxide derivatives: synthesis, characterization and antimycobacterial activity. Met. Ions Biol. Med. $10,867-872$.

Torre, M. H., Gambino, D., Araujo, J., Cerecetto, H., Gonzalez, M., Lavaggi, M. L., et al. (2005). Novel $\mathrm{Cu}(\mathrm{II})$ quinoxaline N1,N4-dioxide complexes as selective hypoxic cytotoxins. Eur. J. Med. Chem. 40, 473-480. doi: 10.1016/j.ejmech.2004.11.012

Torres, E., Moreno-Viguri, E., Galiano, S., Devarapally, G., Crawford, P. W., Azqueta, A., et al. (2013). Novel quinoxaline 1,4-di-N-oxide derivatives as new potential antichagasic agents. Eur. J. Med. Chem. 66, 324-334. doi: 10.1016/j.ejmech.2013.04.065

Troutt, H. F., Hooper, B. E., and Harrington, R. (1974). Effect of carbadox in experimentally induced salmonellosis of swine. J. Am. Vet. Med. Assoc. 164, 402-404.

Urquiola, C., Gambino, D., Cabrera, M., Lavaggi, M. L., Cerecetto, H., Gonzalez, M., et al. (2008). New copper-based complexes with quinoxaline N1,N4-dioxide derivatives, potential antitumoral agents. J. Inorg. Biochem. 102, 119-126. doi: 10.1016/j.jinorgbio.2007. 07.028

Urquiola, C., Vieites, M., Aguirre, G., Marin, A., Solano, B., Arrambide, G., et al. (2006). Improving anti-trypanosomal activity of 3-aminoquinoxaline-2carbonitrile N1,N4-dioxide derivatives by complexation with vanadium. Bioorg. Med. Chem. 14, 5503-5509. doi: 10.1016/j.bmc.2006.04.041

Urquiola, C., Vieites, M., Torre, M. H., Cabrera, M., Lavaggi, M. L., Cerecetto, H., et al. (2009). Cytotoxic palladium complexes of bioreductive quinoxaline N1,N4-dioxide prodrugs. Bioorg. Med. Chem. 17, 1623-1629. doi: 10.1016/j.bmc.2008.12.064
Vicente, E., Charnaud, S., Bongard, E., Villar, R., Burguete, A., Solano, B., et al. (2008). Synthesis and antiplasmodial activity of 3-furyl and 3thienylquinoxaline-2-carbonitrile 1,4-di-N-oxide derivatives. Molecules 13, 6977. doi: $10.3390 /$ molecules 13010069

Vicente, E., Villar, R., Perez-Silanes, S., Aldana, I., Goldman, R. C., and Mong, A. (2011). Quinoxaline 1,4-di-N-oxide and the potential for treating tuberculosis. Infect. Disord. Drug Targets 11, 196-204. doi: 10.2174/187152611795589735

Vieites, M., Noblia, P., Torre, M. H., Cerecetto, H., Laura Lavaggi, M., Costa-Filho, A. J., et al. (2006). Selective hypoxia-cytotoxins based on vanadyl complexes with 3-aminoquinoxaline-2-carbonitrile-N1,N4-dioxide derivatives. J. Inorg. Biochem. 100, 1358-1367. doi: 10.1016/j.jinorgbio.2006.03.012

Villalobos-Rocha, J. C., Sanchez-Torres, L., Nogueda-Torres, B., SeguraCabrera, A., Garcia-Perez, C. A., Bocanegra-Garcia, V., et al. (2014). AntiTrypanosoma cruzi and anti-leishmanial activity by quinoxaline-7-carboxylate 1,4-di-N-oxide derivatives. Parasitol. Res. 113, 2027-2035. doi: 10.1007/s00436014-3850-8

Voogd, C. E., van der Stel, J. J., and Jacobs, J. J. (1980). The mutagenic action of quindoxin, carbadox, olaquindox and some other $\mathrm{N}$-oxides on bacteria and yeast. Mutat. Res. 78, 233-242. doi: 10.1016/0165-1218(80)90104-4

Wang, J., Biedermann, K. A., and Brown, J. M. (1992). Repair of DNA and chromosome breaks in cells exposed to SR 4233 under hypoxia or to ionizing radiation. Cancer Res. 52, 4473-4477.

Wang, J., Biedermann, K. A., Wolf, C. R., and Brown, J. M. (1993). Metabolism of the bioreductive cytotoxin SR 4233 by tumour cells: enzymatic studies. $\mathrm{Br}$. J. Cancer 67, 321-325. doi: 10.1038/bjc.1993.59

Wang, X., Fang, G. J., Wang, Y. L., Ihsan, A., Huang, L. L., Zhou, W., et al. (2011a). Two generation reproduction and teratogenicity studies of feeding cyadox in Wistar rats. Food Chem. Toxicol. 49, 1068-1079. doi: 10.1016/j.fct.2011.01.014

Wang, X., He, Q. H., Wang, Y. L., Ihsan, A., Huang, L. L., Zhou, W., et al. (2011b). A chronic toxicity study of cyadox in Wistar rats. Regul. Toxicol. Pharmacol. 59, 324-333. doi: 10.1016/j.yrtph.2010.11.004

Wang, X., Huang, X. J., Ihsan, A., Liu, Z. Y., Huang, L. L., Zhang, H. H., et al. (2011c). Metabolites and JAK/STAT pathway were involved in the liver and spleen damage in male Wistar rats fed with mequindox. Toxicology 280, 126-134. doi: 10.1016/j.tox.2010.12.001

Wang, X., Wan, D., Ihsan, A., Liu, Q., Cheng, G., Li, J., et al. (2015a). Mechanism of adrenocortical toxicity induced by quinocetone and its bidesoxy-quinocetone metabolite in porcine adrenocortical cells in vitro. Food Chem. Toxicol. 84, 115-124. doi: 10.1016/j.fct.2015.08.016

Wang, X., Zhang, H., Huang, L., Pan, Y., Li, J., Chen, D., et al. (2015b). Deoxidation rates play a critical role in DNA damage mediated by important synthetic drugs, quinoxaline 1,4-dioxides. Chem. Res. Toxicol. 28, 470-481. doi: $10.1021 / \mathrm{tx} 5004326$

Wang, X., Zhang, W., Wang, Y. L., Ihsan, A., Dai, M. H., Huang, L. L., et al. (2012). Two generation reproduction and teratogenicity studies of feeding quinocetone fed to Wistar rats. Food Chem. Toxicol. 50, 1600-1609. doi: 10.1016/j.fct.2011.12.039

Wang, X., Zhang, W., Wang, Y., Peng, D., Ihsan, A., Huang, X., et al. (2010). Acute and sub-chronic oral toxicological evaluations of quinocetone in Wistar rats. Regul. Toxicol. Pharmacol. 58, 421-427. doi: 10.1016/j.yrtph.2010.08.008

Weng, Q., Zhang, J., Cao, J., Xia, Q., Wang, D., Hu, Y., et al. (2011). Q39, a quinoxaline 1,4-Di-N-oxide derivative, inhibits hypoxia-inducible factor1alpha expression and the Akt/mTOR/4E-BP1 signaling pathway in human hepatoma cells. Invest. New Drugs 29, 1177-1187. doi: 10.1007/s10637-010$9462-\mathrm{y}$

WHO (1991). Toxicological evaluation of certain veterinary drug residues in food Carbadox. WHO Food Addit. Ser. 27, 694.

WHO (1994). Toxicological evaluation of certain veterinary drug residues in food. WHO Food Addit. Ser. 33, 804-817.

WHO (2011). "Global tuberculosis control 2011," in The Sixteenth Global Report on Tuberculosis (Geneva: World Health Organization).

Yadav, P., Marshall, A. J., Reynisson, J., Denny, W. A., Hay, M. P., and Anderson, R. F. (2014). Fragmentation of the quinoxaline N-oxide bond to the $\mathrm{OH}$ radical upon one-electron bioreduction. Chem. Commun. (Cambridge, Engl.) 50, 13729-13731. doi: 10.1039/c4cc05657d

Yen, J. T., and Pond, W. G. (1993). Effects of carbadox, copper, or Yucca schidigera extract on growth performance and visceral weight of young pigs. J. Anim. Sci. $71,2140-2146$. 
Yin, J., Glaser, R., and Gates, K. S. (2012). On the reaction mechanism of tirapazamine reduction chemistry: unimolecular $\mathrm{N}-\mathrm{OH}$ homolysis, stepwise dehydration, or triazene ring-opening. Chem. Res. Toxicol. 25, 634-645. doi: 10.1021/tx200546u

Zanetti, S., Sechi, L. A., Molicotti, P., Cannas, S., Bua, A., Deriu, A., et al. (2005). In vitro activity of new quinoxalin 1,4-dioxide derivatives against strains of Mycobacterium tuberculosis and other mycobacteria. Int. J. Antimicrob. Agents 25, 179-181. doi: 10.1016/j.ijantimicag.2004. 11.003

Zarranz, B., Jaso, A., Aldana, I., and Monge, A. (2003). Synthesis and antimycobacterial activity of new quinoxaline-2-carboxamide 1,4-di-Noxide derivatives. Bioorg. Med. Chem. 11, 2149-2156. doi: 10.1016/S09680896(03)00119-6

Zarranz, B., Jaso, A., Aldana, I., and Monge, A. (2004). Synthesis and anticancer activity evaluation of new 2-alkylcarbonyl and 2-benzoyl-3-trifluoromethylquinoxaline 1,4-di-N-oxide derivatives. Bioorg. Med. Chem. 12, 3711-3721. doi: 10.1016/j.bmc.2004.04.013

Zarranz, B., Jaso, A., Aldana, I., Monge, A., Maurel, S., Deharo, E., et al. (2005). Synthesis and antimalarial activity of new 3-arylquinoxaline-2-carbonitrile derivatives. Arzneimittelforschung 55, 754-761.

Zeman, E. M., Brown, J. M., Lemmon, M. J., Hirst, V. K., and Lee, W. W. (1986). SR-4233: a new bioreductive agent with high selective toxicity for hypoxic mammalian cells. Int. J. Radiat. Oncol. Biol. Phys. 12, 1239-1242. doi: 10.1016/0360-3016(86)90267-1

Zhang, C., Wang, C., Tang, S., Sun, Y., Zhao, D., Zhang, S., et al. (2013). TNFR1/TNF-alpha and mitochondria interrelated signaling pathway mediates quinocetone-induced apoptosis in HepG2 cells. Food Chem. Toxicol. 62, 825838. doi: 10.1016/j.fct.2013.10.022

Zhang, H. (2012). The Study of Antibacterial Mechanism of Cyadox on Escherichia coli. Wuhan: Huazhong Agricultural University.
Zhang, J., Cao, J., Weng, Q., Wu, R., Yan, Y., Jing, H., et al. (2010). Suppression of hypoxia-inducible factor lalpha (HIF-1alpha) by tirapazamine is dependent on eIF2alpha phosphorylation rather than the mTORC1/4E-BP1 pathway. PLoS ONE 5:e13910. doi: 10.1371/journal.pone.0013910

Zhang, K., Zheng, W., Zheng, H., Wang, C., Wang, M., Li, T., et al. (2014). Identification of oxidative stress and responsive genes of HepG2 cells exposed to quinocetone, and compared with its metabolites. Cell Biol. Toxicol. 30, 313-329. doi: 10.1007/s10565-014-9287-0

Zhao, D., Wang, C., Tang, S., Zhang, C., Zhang, S., Zhou, Y., et al. (2015). Reactive oxygen species-dependent JNK downregulated olaquindox-induced autophagy in HepG2 cells. J. Appl. Toxicol. 35, 709-716. doi: 10.1002/jat.3022

Zou, J., Chen, Q., Jin, X., Tang, S., Chen, K., Zhang, T., et al. (2011). Olaquindox induces apoptosis through the mitochondrial pathway in HepG2 cells. Toxicology 285, 104-113. doi: 10.1016/j.tox.2011.04.010

Zou, J., Chen, Q., Tang, S., Jin, X., Chen, K., Zhang, T., et al. (2009). Olaquindoxinduced genotoxicity and oxidative DNA damage in human hepatoma G2 (HepG2) cells. Mutat. Res. 676, 27-33. doi: 10.1016/j.mrgentox.2009. 03.001

Conflict of Interest Statement: The authors declare that the research was conducted in the absence of any commercial or financial relationships that could be construed as a potential conflict of interest.

Copyright (C) 2016 Cheng, Sa, Cao, Guo, Hao, Liu, Wang and Yuan. This is an open-access article distributed under the terms of the Creative Commons Attribution License (CC BY). The use, distribution or reproduction in other forums is permitted, provided the original author(s) or licensor are credited and that the original publication in this journal is cited, in accordance with accepted academic practice. No use, distribution or reproduction is permitted which does not comply with these terms. 